TAPIA, Patricia: "El discurso de odio del art. 510.1.a) del Código Penal español: la

ideología como un Caballo de Troya entre las circunstancias sospechosas de discriminación".

Polít. Crim. Vol. 16, № 31 (Junio 2021), Art. 11, pp. 284-320

[http://politcrim.com/wp-content/uploads/2021/07/Vol16N31A11.pdf]

\title{
El discurso de odio del art. 510.1.a) del Código Penal español: la ideología como un Caballo de Troya entre las circunstancias sospechosas de discriminación"
}

\section{The Hate Speech of Article 510.1.a) of the Spanish Criminal Code: Ideology as a Trojan Horse within Suspect Circunmstances of Discrimination}

\author{
Dra. Patricia Tapia Ballesteros \\ Profesora Titular de Derecho Penal Universidad de Valladolid, España \\ patricia.tapia@uva.es \\ https://orcid.org/0000-0001-5234-7469
}

\section{Resumen}

Fecha de recepción: 25/06/2020.

Fecha de aceptación: 23/09/2020.

Con la reforma del artículo 510.1.a) del Código Penal español en el año 2015, se alentó una peligrosa tendencia entre los medios de comunicación y, lo que es más grave, en los operadores jurídicos: calificar como delito de discurso de odio toda expresión o manifestación hiriente, ofensiva o de dudoso humor. Para ello, se ha utilizado la circunstancia sospechosa de discriminación de la ideología, prevista en el catálogo del citado precepto, como un auténtico caballo de Troya con el que acceder a esta categoría delictiva. Teniendo en cuenta este contexto, en el trabajo que se presenta, nos proponemos: por un lado, poner de manifiesto los problemas de delimitación e inseguridad jurídica derivados de la regulación vigente $\mathrm{y}$, por otro, advertir sobre las consecuencias de la interpretación del precepto por considerarlo delito de odio en vez de delito antidiscriminatorio, como venía haciéndose en España desde 1995.

Palabras clave: delito de discurso de odio, delito antidiscriminatorio, Caso Alsasua, incitación a la discriminación

\begin{abstract}
Article 510.1.a) of the Spanish Criminal Code was modified in 2015, creating a dangerous trend among the media and, even worse, among legal practitioners: any harmful or offensive expression or questionable humor turns into hate speech crime. In order to do this, the suspect circunmstance of ideological discrimination (included in art. 510 catalogue) is used as a real Trojan Horse. In this context, this paper aims to reveal the problems related to the legal delimitation and legal uncertainty arising from the reform. Also, this paper discusses the interpretative consequences by using hate crime category instead of anti-discrimination crime, as it has been doing in Spain since 1995.
\end{abstract}

\footnotetext{
* Este trabajo se enmarca dentro de los Proyectos de Investigación "Garantías procesales de investigados y acusados: la necesidad de armonización y fortalecimiento en el ámbito Unión Europea" (DER2016-78096-P).
} 


\section{TAPIA, Patricia: "El discurso de odio del art. 510.1.a) del Código Penal español: la ideología como un Caballo de Troya entre las circunstancias sospechosas de discriminación".}

Keywords: Hate speech crime, Anti-dscrimination crime, Alsasua case, Incitement to discrimination.

\section{Introducción}

El artículo 510 del Código Penal español se vio ampliamente modificado a partir de la reforma de la Ley Orgánica 1/2015, de 30 de marzo. Tanto es así que, desde la aprobación del Código Penal de 1995 hasta la citada reforma, existen contadas sentencias relativas a la provocación al odio, a la discriminación o a la violencia mientras que, con la entrada en vigor de la nueva regulación, el número de denuncias y condenas no ha parado de aumentar.

Entendemos que un claro desencadenante ha sido la incorporación generalizada de las expresiones "delito de odio" y "delito de discurso de odio" en los medios de comunicación, ${ }^{1}$ pero también entre los operadores jurídicos ${ }^{2}$ a través de una interpretación expansiva de todos los tipos delictivos que, de alguna manera, criminalizan conductas situadas muy cerca del ámbito artístico, la crítica política o la opinión contestataria. ${ }^{3}$ De este modo, se ha creado un totum revolutum de conductas o manifestaciones cuyo denominador común es la concurrencia de un supuesto sentimiento de odio en el autor hacia la víctima o las víctimas. ${ }^{4}$

Así, con independencia del recorrido judicial concreto que hayan tenido, se han calificado como delito de discurso de odio, las declaraciones vertidas en Twitter y Facebook instando a los hoteleros catalanes a expulsar a los policías y guardias civiles que se encontraban alojados en sus establecimientos en torno al 1 de octubre, ${ }^{5}$ el denominado caso Blanquerna ${ }^{6}$ y las publicaciones contra los catalanes fallecidos en el vuelo Germanwings. ${ }^{7}$ También se ha vinculado el discurso de odio a manifestaciones ofensivas contra el colectivo LGTBI, como fue el caso del video publicado en Youtube bajo el título "Sodomía y pederastia son dos

\footnotetext{
${ }^{1}$ GORJÓN (2019), pp. 58-59, advierte de la importancia del auge del uso de internet y de las redes sociales en los delitos de odio y de discurso de odio (delitos de ciberodio, estudiados por la autora señalada). Véase, también, MORETÓN (2012), pp. 1-18; MIRÓ (2017), pp. 32-59; entre otros.

${ }^{2}$ Así, GÓMEZ (2018), pp. 411-449.

${ }^{3}$ LAURENZO (2019), p. 453, advierte que resulta obligatorio una interpretación restrictiva de "los tipos penales que rozan ámbitos tan sensibles como la creación artística, la crítica política o, en general, la opinión contestataria". También, DAUNIS (2020), pp. 1050-1053, donde identifica tres grupos de delitos situados dentro de la categoría de delitos de odio, en los que se confunde "el odio como sentimiento con el odio como delito".

Véase el análisis que realiza GORJÓN (2018), pp. 623-626, sobre los datos del Anuario estadístico del Ministerio del Interior desde el año 2013 al 2016

${ }^{4}$ MORETÓN (2012), p. 6, advierte del peligro de la expresión "crímenes o delitos de odios" ya que, aunque "tomada en sentido literal, resulta equívoca, pues el odio al que se alude es una particular actitud subjetiva del agresor que puede no coincidir con el odio en sentido usual del término que, a su vez, no es patrimonio exclusivo de estas agresiones".

${ }^{5}$ Auto del Tribunal Superior de Justicia de Cataluña (Sala de lo Civil y de lo Penal, Sección 1ª), 72/2018, de 28 de junio, se inadmite la querella.

${ }^{6}$ Caso que, conforme a la Sentencia del Tribunal Constitucional 1/2020, de 14 de enero, debe volver a evaluarse en lo que a la aplicación del artículo 22.4 del Código Penal se refiere (entre otras cuestiones).

${ }^{7}$ Sentencia del Juzgado de Instrucción de Cerdanyola del Vallès (Provincia de Barcelona) 25/2017, de 15 marzo. Se dictó Sentencia por conformidad por lo que no se llegó a analizar el fondo del asunto.
} 


\section{Polít. Crim. Vol. 16, № 31 (Junio 2021), Art. 11, pp. 284-320 [http://politcrim.com/wp-content/uploads/2021/07/Vol16N31A11.pdf]}

ramas del mismo tronco"; $; 8$ o contra los migrantes, ${ }^{9}$ o en relación con cualquier religión, incluida la Católica; ${ }^{10}$ contra las mujeres: $;{ }^{11}$ contra víctimas del terrorismo o enaltecimiento del mismo, como los casos Cassandra, ${ }^{12}$ Valtonyc ${ }^{13}$ o Def con Dos; ${ }^{14}$ así como contra los toreros $;{ }^{15}$ contra los miembros de las Fuerzas y Cuerpos de Seguridad del Estado; o, incluso, la Corona. ${ }^{16}$

La realidad es que se ha despertado una mayor sensibilidad hacia estas conductas y, por ello, se denuncia y se persigue más. Lo que no quiere decir que todos los actos que son calificados por los medios de comunicación, e incluso por los operadores jurídicos, como delitos de odio colmen los tipos. Esto ha generado dos sensaciones antagónicas dentro de la sociedad.

Por un lado, se tiene la sensación de que se ha instaurado una censura punitiva hacia todo lo políticamente incorrecto. ${ }^{17}$ Chistes, comentarios, normalizados por su uso, como el desafortunado twit sobre Irene Villa y las niñas de Alcacer, publicado por el ex-edil del

${ }^{8}$ Puede verse Sentencia de la Audiencia Provincial de Madrid (Sección 23a) 762/2017, de 29 diciembre. En ella se desestima recurso contra la condena por un delito del artículo 510.2 del Código Penal.

${ }^{9}$ Sentencia de la Audiencia Provincial de Santa Cruz de Tenerife (Sección 2a) 107/2014, de 7 de marzo. Se confirmó la Sentencia de primera instancia donde se había entendido que constituía un delito del artículo 510.1 del Código Penal la publicación en un periódico de un poema de claro contenido xenófobo.

${ }^{10}$ Auto del Juzgado de Instrucción de Pamplona de 10 de noviembre de 2016, archivó la causa contra el artista que escribió la palabra "pederastia" con hostias consagradas. También se archivó el caso del beso lésbico de las Vírgenes por Auto del Juzgado de Instrucción de Valencia, de 23 de junio de 2016.

${ }^{11}$ La Sección $1^{\text {a }}$ de la Audiencia Provincial de las Islas Baleares, en Sentencia 312/2013, de 10 de diciembre absolvió a dos personas que habían publicado en la web de un partido político una animación donde se mostraban veinte maneras de morir una mujer. Por su parte, la Sala de lo Penal (Sección 1 $1^{\text {a }}$ ) del Tribunal Supremo, en Sentencia 72/2018, de 9 de febrero, condena a un sujeto por realizar manifestaciones en Twitter, calificadas como de machistas terroristas.

${ }^{12}$ En el caso de Cassandra, se trataba de comentarios calificados como chistes y repetidos en el ámbito social de manera habitual. Cassandra fue absuelta en Sentencia de la Sala de lo Penal (Sección $1^{\mathrm{a}}$ ) del Tribunal Supremo 95/2018, de 26 de febrero.

Véase, entre otros, GÓMEZ (2018), pp. 420-421.

${ }^{13}$ Los hechos por los que fue condenado por un delito de enaltecimiento del terrorismo o humillación a las víctimas en Sentencia del Tribunal Supremo, Sala de lo Penal, 4/2017, se produjeron entre los años 2012 y 2014.

${ }^{14}$ Los hechos por los que fue condenado por enaltecimiento del terrorismo en Sentencia de la Audiencia Nacional, Sección $2^{\mathrm{a}}$, de 21 de febrero de 2017, se realizaron entre los años 2012 y 2013 . Fallo que fue objeto de recurso de casación ante el Tribunal Supremo, el cual fue desestimado en Sentencia de la Sala de lo Penal 79/2018, de 15 de febrero. El Tribunal Constitucional, en Sentencia de 25 de febrero de 2020 ha declarado que había sido vulnerado el derecho a la libertad de expresión.

GÓMEZ (2018), pp. 421-423.

${ }^{15}$ Sentencia del Juzgado de lo Penal de Segovia 419/2019, de 15 de noviembre, por la que se absuelve por "el delito de odio del art. 510.1.a, 3, 5 y 6, [...] y art. 510.2.a", relativa al caso del torero Víctor Barrio y la Sentencia del Juzgado de lo Penal de Valencia, de 19 de septiembre de 2019, en la que se resuelve también la absolución del delito previsto en el artículo 510, sobre el niño Adrián.

${ }^{16}$ Así se calificaron los hechos que integran el caso Stern Taulats y Roura Capellera, por la Audiencia Nacional en Sentencia 40/2008, de 9 de julio. Se denegó el recurso de amparo en Sentencia del Tribunal Constitucional 177/2015, de 22 de julio. Sin embargo, el Tribunal Europeo de Derechos Humanos, en Sentencia 2018/27, de 13 de marzo, estableció que los hechos se enmarcaban dentro de la libertad de expresión.

Por otro lado, en las últimas semanas, se pretende considerar delito de odio, también, determinados actos dirigidos contra el personal esencial en la pandemia del Covid 19. Véase: https://tinyurl.com/yeocudxv [visitado el 14.06.2021]; https://tinyurl.com/yjxku4d6 [visitado el 14.06.2021]

${ }^{17} \mathrm{O}$, al menos, así se percibe. Sirva de ejemplo https://tinyurl.com/yevrv7a4 [visitado el 14.06.2021]. 


\section{TAPIA, Patricia: "El discurso de odio del art. 510.1.a) del Código Penal español: la ideología como un Caballo de Troya entre las circunstancias sospechosas de discriminación".}

Ayuntamiento de Madrid, Guillermo Zapata, se convierten en típicos o, al menos, en perseguidos penalmente.

Por otro lado, los colectivos susceptibles de ser discriminados no perciben una protección efectiva. Por ejemplo, piensen en el caso del videojuego publicado online, hace unos años, en el marco de la campaña electoral de Cataluña, en el que Alicia Sánchez Camacho, caracterizada como Lara Croft, iba subida a una gaviota llamada Pepe, y desde ella disparaba a los considerados enemigos, estos son, independentistas e inmigrantes ilegales. En este caso, la querella directamente se inadmitió. ${ }^{18}$

Esta percepción social, así como la falta de seguridad jurídica derivada de la nueva redacción del artículo 510, ha motivado que la Fiscalía General del Estado haya publicado una circular de casi noventa páginas para aclarar cómo debe interpretarse el precepto. ${ }^{19} \mathrm{Si}$ bien, como tendremos oportunidad de señalar, las pautas establecidas configuran un delito excesivamente amplio y, bajo nuestro punto de vista, deslegitimado.

Dentro del amplio precepto, nos disponemos a prestar especial atención la previsión del artículo 510.1.a), por considerarse el delito de discurso de odio por antonomasia y ser el más reclamado en las situaciones descritas con anterioridad. En concreto, nos centraremos en la delimitación del bien jurídico protegido y el sujeto pasivo, donde, entendemos, cuenta con un papel fundamental la delimitación de la ideología, a través de la cual se quiere convertir en delito de discurso de odio o, en general, delito de odio, cualquier conducta revestida de un sentimiento negativo. Seguidamente, se analizarán la acción típica y las modalidades agravadas específicas, la penalidad prevista y algunos problemas concursales.

Entendemos que, en un trabajo de esta extensión, no merece la pena detenerse en el estudio del tipo subjetivo, se trata de un delito evidentemente doloso, ni en analizar la antijuridicidad ni la culpabilidad, ya que no tiene sentido admitir causas de justificación o de exculpación. Tampoco se admiten formas imperfectas de ejecución y no se identifican problemas específicos de autoría y participación, más allá de la responsabilidad penal derivada de retwittear. En el Código Penal no se distingue entre quien escribe el mensaje en su red social y quien participa en su difusión mediante retwits. A priori, ambos se considerarían autores del delito. Si bien es cierto que podría plantearse un problema en aquellos supuestos en los que se retwittea con la finalidad de denunciar la declaración realizada por quien lo ha escrito. $^{20}$

\footnotetext{
${ }^{18}$ Auto del Tribunal Superior de Justicia de Cataluña (Sala de lo Civil y Penal, Sección $1^{\text {a }}$ ), de 3 de marzo de 2011. Se entendió que los disparos no iban dirigidos contra el grupo o colectivo de inmigrantes sino contra la ilegalidad

${ }^{19}$ Circular 7/2019, de 14 de mayo, sobre pautas para interpretar los delitos de odio tipificados en el art. 510 CP.

${ }^{20}$ Advierte GOYENA (2018), passim, que no es relevante el estar de acuerdo con el mensaje de odio y se remite a la Sentencia del Tribunal Supremo 706/2017, de 27 de octubre, donde se establece que "basta que de un modo u otro accedan a [el mensaje], y les dé publicidad, expandiendo el mensaje a gran cantidad de personas".
} 


\section{Polít. Crim. Vol. 16, № 31 (Junio 2021), Art. 11, pp. 284-320 [http://politcrim.com/wp-content/uploads/2021/07/Vol16N31A11.pdf]}

\section{Origen y fundamento del precepto}

La regulación vigente del artículo 510 del Código Penal español es fruto de la reforma del Código Penal operada mediante la Ley Orgánica 1/2015, de 30 de marzo. En este precepto se sanciona un amplio catálogo de conductas vinculadas, de un modo u otro, a la creación de una situación o contexto de odio, hostilidad, discriminación o violencia hacia un determinado colectivo, caracterizado por ostentar alguna de las circunstancias sospechosas de discriminación comprendidas en el catálogo del mismo precepto.

Aunque de un modo más restrictivo, la tipificación de estas prácticas ya se contemplaba en el Código Penal anterior. Concretamente, a través de la Ley Orgánica 4/1995, de 11 de mayo, se incorporó el artículo 165 ter, en el que se recogía el delito de provocación a la discriminación. ${ }^{21}$ La razón de ser de este delito se fundamentó en la proliferación de episodios racistas y xenófobos y el apogeo de grupos organizados de ideología neonazi en la década de los noventa. En España, sin lugar a dudas, el célebre caso de Violeta Friedman, supuso un punto de inflexión. ${ }^{22}$

Con la aprobación del Código Penal de 1995, la apuesta por la lucha contra la discriminación mediante el Derecho Penal se consolida con la creación de un amplio elenco de delitos antidiscriminatorios ${ }^{23}$ diseminados a lo largo de todo el texto legislativo, entre los cuales se mantuvo, en términos muy similares a los del artículo 165 ter, el delito de provocación a la discriminación en el artículo 510. No obstante, este precepto fue objeto de importantes debates doctrinales.

La mayor polémica giró en torno al alcance que debía atribuirse al término "provocación", que integraba el núcleo de la acción típica del apartado primero del artículo 510: "Los que provocaren a la discriminación, al odio o a la violencia". Al respecto se desarrollaron dos posiciones contrapuestas: ¿Constituía un delito autónomo ${ }^{24}$ o se trataba de un acto preparatorio y debía, por tanto, realizarse una remisión al artículo 18.1 del Código Penal ?25

Junto a lo anterior, se discutía también si para consumar el tipo era necesario que el mensaje incitador llegase a sus destinatarios. Algunos autores entendían que sí y, además, exigían que estos resolvieran cometer actos de violencia o de discriminación. ${ }^{26}$

Por nuestra parte, en su momento manifestamos que se trataba de un delito de aptitud o de peligro hipotético, en el que, por lo tanto, no se exige la efectiva lesión del bien jurídico. De este modo, no resultaba necesario acreditar que el mensaje había llegado a sus destinatarios ni mucho menos que estos decidiesen realizar actos delictivos, cosa que tampoco se exigía, ni se exige, en el artículo 18 del Código Penal español. Siendo esto así, bastaría con que la conducta fuera idónea para afectar al bien jurídico protegido. Esta posición, sin embargo,

\footnotetext{
${ }^{21}$ Sobre los antecedentes legislativos del precepto, LANDA (2001), pp. 117-138.

${ }^{22}$ Sentencia del Tribunal Constitucional 214/1991, de 11 de noviembre.

${ }^{23}$ Ampliamente, BERNAL (1998), pp. 162; nosotros nos hemos referido en TAPIA (2014), pp. 173-195.

${ }^{24}$ DEL ROSAL (2004), p. 1038; CÓRDOBA y GARCÍA (2004), p. 2427.

${ }^{25}$ BERNAL (1998), p. 77; SERRANO y SERRANO (2007), p. 947

${ }^{26}$ DEL ROSAL (2004), p. 1038; CÓRDOBA y GARCÍA (2004), p. 2427; entre otros.
} 


\section{TAPIA, Patricia: "El discurso de odio del art. 510.1.a) del Código Penal español: la ideología como un Caballo de Troya entre las circunstancias sospechosas de discriminación".}

supone reconocer que el tipo representa un adelantamiento desmesurado de las barreras de protección. El artículo 510 realizaba una descripción vaga de las conductas típicas y esta falta de precisión, como veremos, se mantiene en la regulación vigente a pesar de la modificación del verbo rector.

\section{Bien jurídico protegido}

Entrando ya en el análisis dogmático del artículo 510 del Código Penal, existe una importante discusión doctrinal en torno al bien jurídico que protege. La ubicación sistemática del precepto suele ser un indicativo de, al menos, la pretensión del legislador. Sin embargo, en el delito objeto de estudio, la rúbrica resulta demasiado amplia: "De los delitos cometidos con ocasión del ejercicio de los derechos fundamentales y de las libertades públicas garantizados por la Constitución”.

Con el objeto de limitarla, un amplio sector doctrinal ha utilizado de guía la Sentencia del Tribunal Constitucional 214/1991, de 11 de enero, referida al caso de Violeta Friedman, en la que se puso el foco de atención en el honor, la dignidad y la igualdad ${ }^{27}$. En esta línea se manifiestan autores como Aguilar. ${ }^{28}$

Sin embargo, resulta más habitual en la doctrina encontrar propuestas en las que se identifica un único bien jurídico o, al menos, un bien jurídico principal. De este modo, De Pablo considera que el honor, entendido como la legítima expectativa de reconocimiento que merece todo ciudadano como miembro de pleno derecho de una comunidad jurídica, cuenta con la entidad suficiente para limitar la libertad de expresión. ${ }^{29}$ Por su parte, autores como Brandariz o Cámara parecen optar por la dignidad como objeto de tutela. Si bien, el primero de ellos defiende que los delitos de odio deben restringirse a la tutela de "bienes jurídicos eminentemente personales", ${ }^{30}$ mientras que Cámara admite la posibilidad de que se lesione algún otro bien jurídico de carácter no personal. ${ }^{31}$

Pero sin lugar a dudas, el mayor consenso se sitúa en la consideración de la igualdad y la no discriminación como bienes jurídicos protegidos en este ámbito. Aunque no quiere decir que no existan importantes matices diferenciadores entre sus defensores. Podríamos distinguir, claramente, dos bloques según se equipare la no discriminación con la igualdad o se entienda que la no discriminación se reserva para determinados colectivos.

A favor del bien jurídico de la igualdad y la no discriminación, como términos equivalentes, entendemos que se sitúa la Circular de la Fiscalía General del Estado 7/2019, al afirmar que "una adecuada exégesis del origen y fundamento de los delitos de odio no puede obviar que

\footnotetext{
${ }^{27}$ Sobre ello nos pronunciamos en DE PABLO y TAPIA (2017), pp. 1-4.

${ }^{28}$ AGUILAR (2015), pp. 43-44

${ }^{29}$ DE PABLO (2018), p. 238.

${ }^{30}$ BRANDARIZ (2010), p. 48.

${ }^{31}$ CÁMARA (2017), p. 172. Véase el interesante recorrido sobre las propuestas doctrinales relacionadas con el bien jurídico, pp. 172-175.
} 


\section{Polít. Crim. Vol. 16, № 31 (Junio 2021), Art. 11, pp. 284-320 [http://politcrim.com/wp-content/uploads/2021/07/Vol16N31A11.pdf]}

la igualdad y la no discriminación sólo pueden ser consideradas como una expresión de la propia dignidad humana". ${ }^{32}$

En frente se sitúan Laurenzo o Bernal con una concepción de la no discriminación autónoma de la igualdad. Laurenzo considera que la conducta discriminatoria "implica una negación de la igualdad entre todos los seres humanos basada en ciertos rasgos o peculiaridades que distinguen al discriminado del modelo de normalidad que se toma como punto de referencia". ${ }^{33}$ Siendo esto así, entiende la autora que solo determinados colectivos pueden ser objeto de trato discriminatorio y que este afectará al derecho a ser tratado como un ser humano igual a los demás. De este modo, se tratará de un bien jurídico individual, aunque pueda verse lesionado a través de conductas dirigidas a un grupo. ${ }^{34}$ No obstante, Laurenzo defiende que, junto a esta dimensión individual del bien jurídico, también se puede lesionar como consecuencia de un acto discriminatorio un bien jurídico colectivo, "el modelo de convivencia plural y multicultural del que parte nuestra Constitución". ${ }^{35}$ Por su parte, Bernal defiende una fundamentación personalista del derecho a no ser discriminado, lo que supone que el trato desigual que integra la discriminación cuente con una motivación o razón "rechazable de lo que es propio del sujeto pasivo y que expresa su ser personal". ${ }^{36} \mathrm{Si}$ bien, reconoce la relación del titular del bien jurídico con un grupo o minoría que, de modo implícito, se tutela también. ${ }^{37}$

Una posición similar se defiende aquí. Bajo nuestro punto de vista, el artículo 510, tanto antes de la reforma de 2015 como en su regulación vigente, forma parte del catálogo de delitos antidiscriminatorios $\mathrm{y}$, por lo tanto, el bien jurídico protegido será el valor no ser discriminado. Entendemos que esto es así porque lo fundamental es que el mensaje o el acto realizado que colma cualquiera de los tipos penales que se contemplan en el precepto, son punibles solo porque van dirigidos a una persona o grupo de personas que se caracterizan por ostentar una determinada circunstancia física, ideológica o social. Sin esta selección, los hechos serían constitutivos de otro delito o directamente atípicos.

De este modo, el valor no ser discriminado, como bien jurídico protegido, cuenta con una doble dimensión. Por un lado, una dimensión individual, ya que la conducta discriminatoria va dirigida a una persona concreta que es, precisamente, quien la soporta de forma directa e inmediata. Y, por otro, una dimensión colectiva, en la medida en que el colectivo, la minoría, ${ }^{38}$ que ostenta la circunstancia sospechosa de discriminación, se ve afectado porque

\footnotetext{
${ }^{32}$ Circular 7/2019, de 14 de mayo, p. 7.

${ }^{33}$ LAURENZO (1996b), pp. 234-235.

${ }^{34}$ LAURENZO (1996b), p. 235.

${ }^{35}$ LAURENZO (1996b), p. 241.

${ }^{36}$ BERNAL (2014), p. 380.

${ }^{37}$ BERNAL (2014), p. 381.

${ }^{38}$ Sobre la dificultad a la hora de definir el término "minoría", ampliamente CISNEROS (2018), pp. 61-78, concluye la autora que, lo relevante en la determinación de una minoría es que "se encuentre en una situación de subordinación”.
} 


\section{TAPIA, Patricia: "El discurso de odio del art. 510.1.a) del Código Penal español: la ideología como un Caballo de Troya entre las circunstancias sospechosas de discriminación".}

un acto discriminatorio contra una persona perpetúa, ayuda a normalizar o ahonda en su status de inferioridad. ${ }^{39}$

Este carácter colectivo del bien jurídico protegido se manifiesta claramente en el delito previsto en el artículo 510 ya que, en todas sus modalidades, se limita el sujeto pasivo en atención a que pertenezca a un grupo que presenta alguna de las circunstancias sospechosas de discriminación del catálogo del precepto o, incluso, la conducta vaya dirigida contra el colectivo en general, no exigiéndose siquiera la individualización de la acción en un sujeto concreto, como sí ocurre en otros delitos antidiscriminatorios.

Obviamente, estamos con Portilla cuando afirma que se trata de un delito pluriofensivo ${ }^{40}$. Bajo nuestro punto de vista, en el artículo 510 se tutela el valor no ser discriminado y, en atención al contexto en el que se desarrolle su puesta en peligro, podrán tutelarse también otros bienes jurídicos, como la integridad física o la vida, pero de forma secundaria, casi accidental o instrumental.

Junto a estas propuestas, están otras que contemplan como bien jurídico protegido uno supraindividual. Es el caso de Landa. El autor defiende que lo que se tutela son "las condiciones de seguridad existencial de grupos o colectivos especialmente vulnerables" ya que, en el artículo 510, se ha reunido el conjunto de discursos de odio, mediante el cual se "busca minar las bases mismas de la convivencia en una sociedad democrática abogando por enfrentar a unos grupos contra otros". ${ }^{41}$ Landa entiende el derecho a la igualdad y a la no discriminación desde una perspectiva individual y por ello lo rechaza como bien jurídico protegido en este precepto ${ }^{42}$.

Consideramos que, en el fondo, nuestra posición no dista tanto de la propuesta de Landa. Lo que, en nuestra terminología, es el grupo que se sitúa en una posición de desventaja o inferioridad, o incluso marginación, dentro de la sociedad, equivaldría a los grupos diana, que denomina el autor. Entendemos que mediante el discurso de odio se lesiona o pone el peligro el valor no ser discriminado porque la selección del sujeto o colectivo al que se dirige el mensaje se debe únicamente a que cuenta con una de las características sospechosas de discriminación mientras que Landa pone la mirada en las consecuencias ulteriores a la lesión o puesta en peligro del bien jurídico no ser discriminado.

\section{Sujeto pasivo: las circunstancias sospechosas de discriminación}

En relación con el sujeto pasivo, antes de la reforma de 2015, se aludía únicamente a "grupos y asociaciones" a los que se vinculaba alguna de las circunstancias sospechosas de discriminación recogidas en el catálogo del precepto. Esto parecía indicar que no podía ser

\footnotetext{
${ }^{39}$ Entiende LAURENZO (1996a), p. 237, que la dimensión colectiva alcanza al modelo de convivencia plural y multicultural del que parte nuestra Constitución. Seguida por autores como RODRÍGUEZ (2007), p. 54, entre otros. En contra de esta doble dimensión MACHADO (2002), pp.131 y ss.

${ }^{40}$ PORTILLA (2015), p. 722.

${ }^{41}$ LANDA (2018), pp. 58-59; previamente en LANDA (2000), pp. 348-351. Así, también ALONSO (2014), pp. 293-294.

${ }^{42}$ LANDA (2001), p. 133
} 
sujeto pasivo una persona individual, lo cual tenía sentido ya que, la acción típica va dirigida a crear un clima determinado contra un colectivo por ostentar unas determinadas características $^{43}$. Sin embargo, autores como MUÑOZ entendieron que esto no obstaba para que el sujeto pasivo pudiera ser también una persona a título individual ${ }^{44}$.

Con la reforma operada mediante la Ley Orgánica 1/2015, desaparecen las dudas especificando que las conductas típicas se dirigirán contra "un grupo, una parte del mismo o contra una persona".

Salvado este problema interpretativo, se mantiene aquel relacionado con la selección del sujeto pasivo por parte del autor. Téngase en cuenta que el artículo 510, en todas las modalidades de acción, alude a "motivos racistas, antisemitas u otros referentes a la ideología, religión o creencias, situación familiar, la pertenencia de sus miembros a un etnia, raza o nación, su origen nacional, su sexo, orientación o identidad sexual, por razones de género, enfermedad o discapacidad", lo que plantea el problema de concretar cada una de estas circunstancias sospechosas de discriminación comprendidas en el catálogo.

A continuación, nos detendremos en cada una de ellas, con el objeto de poner de manifiesto los principales problemas de delimitación que plantean. Si bien, como ya se ha anunciado, prestaremos especial atención a la ideología por ser la vía a través de la cual se pretende convertir en delito de discurso de odio o, en general, en delito de odio, cualquier conducta con tintes odiosos. Estamos con Gorjón cuando advierte que "Los delitos de discurso de odio refieren a una ideología política, pero el problema es diseñar una frontera de cuándo tales expresiones adquieren el matiz delictivo". ${ }^{45}$

Dentro del catálogo podemos identificar algunas circunstancias que guardan cierta relación entre sí o que, incluso, podrían plantear problemas de delimitación o concreción entre ellas. Este es el caso de la referencia a "motivos racistas, antisemitas [...] y pertenencia a una etnia o raza", "pertenencia [...] a una [...] nación, su origen nacional", "ideología, religión o creencias" o "sexo [...] razones de género", "orientación o identidad sexual". A estas circunstancias se suman situación familiar, enfermedad o discapacidad.

Todas estas circunstancias sospechosas de discriminación requieren una delimitación rigurosa que permita identificar al colectivo que se tutela frente a las conductas previstas en los delitos antidiscriminatorio (o delitos de odio), en general, y delitos de discurso discriminatorio (o delitos de discurso de odio) en particular.

\subsection{Motivos racistas, antisemitas y pertenencia a una etnia o raza}

Este conjunto de circunstancias sospechosas de discriminación, en realidad, giran en torno a dos términos: etnia y raza. Resulta habitual su uso indistinto, si bien estamos con Landa

\footnotetext{
${ }^{43}$ En su momento entendimos que si el legislador hubiera querido proteger también a los sujetos a nivel individual lo hubiera redactado concretamente, tal y como ocurre en los artículos 511 y 512. TAPIA (2010), p. 1960.

${ }^{44}$ MUÑOZ (2009), p. 770.

${ }^{45}$ GORJÓN (2019), p. 228.
} 


\section{TAPIA, Patricia: "El discurso de odio del art. 510.1.a) del Código Penal español: la ideología como un Caballo de Troya entre las circunstancias sospechosas de discriminación".}

cuando indica que existen matices diferenciadores importantes entre ambos. Entiende el autor que con etnia se hace referencia a "un grupo con ciertos caracteres propios con independencia de que también tengan un determinado color de piel", mientras que, cuando se utiliza el término "raza", se está haciendo uso de su acepción más precisa, ya que alude a "grupos humanos que se distinguen por el color de la piel"46. De este modo, es admisible la doble referencia dentro del catálogo, si bien un trato discriminatorio por razón de etnia podría comprender el supuesto de discriminación por razón de raza.

Asimismo, la pertenencia a una raza también podría considerarse dentro de motivos racistas. Entendemos que esta última circunstancia es más amplia porque podría comprender aquellos supuestos en los que el sujeto pasivo no pertenece al colectivo susceptible de discriminación, pero sí se le relaciona con él. Imagínese el caso en el que el mensaje va en contra de una persona que es pareja de otra de raza negra. Aunque, por otro lado, el racismo es una ideología. Ideología que, tal y como advierte Landa, contribuye "a asentar valoraciones negativas de jerarquización de grupos en función de caracteres externos como, sobre todo, el color de la piel". Pero no abarca aquellas "basadas en factores de identidad de un grupo según referencias étnicas". ${ }^{47}$ De este modo, por ejemplo, en el caso en el que el mensaje fuera contra la pareja de una persona de etnia gitana, no se consideraría dentro del tipo. Al menos, no mediante "motivos racistas". Cosa distinta es que pudiera reconducirse mediante la circunstancia de la ideología.

Con el objeto de salvar este problema, Machado propone sustituir las circunstancias señaladas por una única referencia a "grupo étnico". Entiende la autora que así se destaca el carácter ideológico-político de las discriminaciones racistas ${ }^{48} \mathrm{o}$, mejor dicho, xenófobas o etnófobas, dentro de las cuales se encuentran las prácticas racistas. ${ }^{49}$

Dicha propuesta nos parece acertada en parte. Consideramos adecuado aludir al "grupo étnico" o, directamente, hacer referencia a circunstancias de pertenencia a una etnia, con la que la discriminación por razón de raza quedaría comprendida también. Si bien, con "grupo étnico" no creemos que se aluda a motivos racistas, xenófobos o etnófobos. Bajo nuestro punto de vista, esto se comprende dentro de la circunstancia de la ideología.

Finalmente, la alusión a motivos antisemitas de manera explícita, consideramos que resulta superflua. Qué duda cabe que se justifica en el contexto en el que se aprueban los delitos antidiscriminatorios. Ya hemos advertido que el caso de Violeta Friedman fue crucial. Pero lo cierto es que no hubiera sido necesario. Los motivos antisemitas hacen referencia a motivos vinculados con los judíos, es decir, con el colectivo de personas que cuentan con una cultura propia, unos rasgos físicos diferenciados y una misma religión. Es decir, se trata de

\footnotetext{
${ }^{46}$ LANDA (2000), pp. 53-55; le sigue GARCÍA (2004), p. 65.

${ }^{47}$ LANDA (2000), pp. 54-55.

${ }^{48}$ MACHADO (2002), p. 213.

${ }^{49}$ LANDA (2000), p. 201, señala que la opción terminológica de "racismo" se debe "en buena medida [al] influjo que - de forma absolutamente dominante excepto en los Estados Unidos- ejerce el modelo legislativo de la Convención de 1965 sobre el legislador interno. La Convención de 1965 hace referencia nominal a lo "racial" pero gira materialmente sobre elementos de diferenciación étnicos"
} 


\section{Polít. Crim. Vol. 16, № 31 (Junio 2021), Art. 11, pp. 284-320 [http://politcrim.com/wp-content/uploads/2021/07/Vol16N31A11.pdf]}

una etnia, por lo que la referencia concreta no solo no es necesaria, sino que puede conllevar problemas interpretativos. Es cierto que, tal y como hemos indicado, no es lo mismo motivos antisemitas que pertenencia al colectivo semita. Pero ambas circunstancias se contemplan de manera genérica en el catálogo del artículo 510.1.a del Código Penal, y en el de todos los delitos antidiscriminatorios, a través de la ideología y de la pertenencia a una etnia.

\subsection{Pertenencia a una nación, su origen nacional}

Hasta la reforma del Código Penal, operada mediante la Ley Orgánica 1/2015, de 30 de marzo, se aludía únicamente al origen nacional. Así, en el texto inicial, el origen nacional se vinculaba a la discriminación por razón de raza o etnia ${ }^{50}$. Debemos tener en cuenta que España, hasta los años 90, se convirtió en receptor de migrantes, principalmente jóvenes del norte de África en busca de un futuro socioeconómico ${ }^{51}$. Pero, esta llegada, se produjo prácticamente al tiempo que se iniciaba y, posteriormente, se desarrollaba una fuerte crisis económica. La confluencia de ambos elementos propició que, paulatinamente, creciera la desconfianza y el desprecio hacia "el otro". 52 Otro procedente del extranjero al que se identificaba físicamente.

Realmente, el origen nacional puede estar relacionado, o no, con la pertenencia a una determinada raza o etnia. Si bien, resulta innegable que los actos discriminatorios suelen ir dirigidos hacia aquellos sujetos que proceden de otras naciones y que pertenecen a otra etnia. En este sentido, estamos con Cachón cuando advierte que los inmigrantes son el colectivo que más sufre una discriminación múltiple. ${ }^{53}$

\footnotetext{
${ }^{50}$ Resulta, y resultaba, habitual que la discriminación se fundamentara en la nacionalidad, la etnia o raza y la religión: Sentencia del Tribunal Superior de Justicia de Castilla y León, Burgos (Sala de lo Civil y Penal, Sección $1^{\text {a }}$ ) 36/2019, de 26 de junio, en la que se admite que colma el delito previsto en el artículo 510.2.a la frase proferida en un bar a una mujer "de raza india", tal y como indica la Sentencia, que acababa de casarse con un hombre de nacionalidad española: "agarras a españoles y has engañado a un español por el dinero, putas indias, putas indias vienen a agarrar a un español para quedarse con su dinero"; Sentencia del Juzgado de lo Penal $n^{\circ}$ 440/2017, de 5 de diciembre, referida a los hechos acaecidos en una calle de Barcelona contra una familia de religión musulmana, estando la mujer visiblemente embarazada. Los acusados "movidos por su profunda animadversión a sus creencias religiosas y a su origen marroquí", les gritaron "Putos musulmanes, que estáis haciendo aquí, iros al desierto", "la mujer, la de la cara tapada, la batman"; o la Sentencia del Juzgado de lo Penal ${ }^{\circ} 22$ de Barcelona, de 11 de diciembre de 2017, se consideró que constituían un delito del artículo 510.1 del Código Penal la publicación en un blog personal denominado "Europa Despierta!" entre enero y junio de 2013 textos dirigidos a difundir de forma masiva e indiscriminada "documentos, imágenes, vídeos, noticias y opiniones de carácter ofensivo, denigrante y vejatorio contra personas de origen extranjero e inmigrantes, que profesasen la religión musulmana, judíos y personas afrodescendientes", al tiempo que se defendía la supremacía de la "raza aria".

${ }^{51}$ Véase CISNEROS (2018), pp. 93-105 donde realiza un estudio relativo a las características cualitativas y cuantitativas de los flujos migratorios en España; también, SANZ (2017), pp. 28-29, advierte que "A la sociedad española el inmigrante le sigue generando desconfianza y son muchos los estereotipos y prejuicios que, aprovechados — cuando no alentados - por los propios gobernantes, justifican la adopción de medidas claramente racistas y xenófobas".

${ }^{52}$ Sobre el cambio producido en España respecto a los inmigrantes y grupos de minorías étnicas durante los años 90, véase BORJA (1999), pp. 224-235.

${ }^{53}$ CACHÓN (2009), p. 231; sin aludir explícitamente a la discriminación múltiple, aunque en un sentido similar LAURENZO (2009), p. 1156.
} 


\section{TAPIA, Patricia: "El discurso de odio del art. 510.1.a) del Código Penal español: la ideología como un Caballo de Troya entre las circunstancias sospechosas de discriminación".}

Como se ha indicado, con la reforma de 2015, se incorporó la circunstancia de pertenencia a una nación. Así, en la actualidad, se alude a pertenencia "a una etnia, raza o nación, su origen nacional". De este modo, el legislador pretende distinguir entre la circunstancia de pertenencia a una nación y origen nacional. Esta doble referencia en el artículo 510 no deja de sorprendernos ya que, por un lado, solo se va a prever en este precepto y, por otro, en los catálogos de los delitos antidiscriminatorios se utiliza indistintamente una u otra. Así, se aludía, y alude, únicamente al origen nacional en el artículo 511, mientras que solo se hace referencia a la nación en los artículos 22, 314, 512 y 515. Siendo esto así, ¿cómo interpretamos ambas circunstancias?

No parece tener sentido que, antes de la reforma, se pretendiera tutelar algo diferente en los artículos 510 y 511 a lo protegido en los demás delitos antidiscriminatorios. Esto se ratifica si tenemos en cuenta que los artículos 511 y 512 tipifican la misma conducta, solo que uno en el ámbito público y el otro en el privado, y en el primero se tutela frente a la discriminación por razón de origen nacional y en el segundo por pertenencia a una nación. Esto puede ser criticable en virtud del principio de taxatividad, pero consideramos que una interpretación teleológica lo admitiría.

El problema está en que, tras la Ley Orgánica 1/2015, al aludirse a ambas circunstancias, no es sostenible una equiparación entre ambas. Roig trata de salvar la duplicidad considerando que con el término "origen nacional" se abarca "la discriminación producida tanto por la nacionalidad actual como por la de nacimiento" de manera que con nación se hace referencia al lugar de origen y la "pertenencia a una nación" como circunstancia independiente resultaría innecesaria ${ }^{54}$. Siendo así, puede entenderse que la doble referencia del 510 trata de especificar o señalar la importancia de la discriminación por el origen nacional. El problema está en que la previsión de ambos términos en el 510 obliga a interpretar de manera diferenciada la referencia a nación y origen nacional en los demás delitos antidiscriminatorios. Llevando al absurdo de que, en el delito antidiscriminatorio de negación de prestación de servicios públicos al que se tiene derecho, del artículo 511, se tutela a quienes son objeto de trato discriminatorio por su nacionalidad actual o por su nacionalidad de nacimiento, mientras que en el de negación de una prestación en el ámbito privado del 512 se tutelaría solo frente a los actos de discriminación por el lugar de origen.

Junto a lo anterior, se plantea otro problema derivado de las particularidades propias del Estado español y las reivindicaciones nacionalistas que en él existen. En este sentido, se discute si con "pertenencia a una nación" u "origen nacional" se comprenden las nacionalidades extranjeras o si tienen cabida, también, las nacionalidades integradas en España. Ante esta polémica, nos parece acertada la respuesta dada por Laurenzo. Entiende la autora que, en el contexto en que nos situamos, "nación" no comprende las nacionalidades internas. Y, para ello, se apoya en el artículo 2 de la Constitución en el que se equiparan "nacionalidades y regiones". Laurenzo considera que "si se extendiera la protección penal a los ciudadanos de determinadas nacionalidades internas lo mismo debería hacerse con

\footnotetext{
${ }^{54}$ ROIG (2015), pp. 1256.
} 


\section{Polít. Crim. Vol. 16, No 31 (Junio 2021), Art. 11, pp. 284-320 [http://politcrim.com/wp-content/uploads/2021/07/Vol16N31A11.pdf]}

quienes se ven marginados por pertenecer a alguna región del Estado, ya que la Constitución las equipara". 55

\subsection{Sexo, razones de género}

El sexo, como circunstancia sospechosa de discriminación, no se contemplaba en el artículo 165 ter del Código Penal anterior, incorporado mediante la Ley Orgánica 4/1995, de 11 de mayo. Sin embargo, en la discusión parlamentaria del Código Penal de 1995 se introdujo en todos los delitos antidiscriminatorios. Esto tiene pleno sentido conforme a la Sentencia del Tribunal Constitucional 128/1987, de 16 de julio, en la que se reconocía que "la discriminación por razón de sexo halla su razón concreta en la voluntad de terminar con la histórica situación de inferioridad en que, en la vida social y jurídica, se había colocado a la población femenina"

De este modo, los actos discriminatorios por razón de sexo podían vincularse a aspectos relacionados con la biología, ${ }^{57}$ pero también con los prejuicios sociales hacia las capacidades de las mujeres, los cuales representan el principal motivo discriminatorio. ${ }^{58}$

Con la Ley Orgánica 1/2015, de 30 de marzo, junto al sexo, se incorpora al artículo 510 la circunstancia de razones de género. ${ }^{59}$ Tal y como se reconoce en su Exposición de Motivos, ${ }^{60}$ el género se entiende como "los papeles, comportamientos o actividades y atribuciones socialmente construidos que una sociedad concreta considera propios de mujeres o de hombres", tal y como se manifiesta en el Convenio $\mathrm{n}^{\circ} 210$ del Consejo de Europa sobre prevención y lucha contra la violencia contra las mujeres y la violencia doméstica, aprobado en Estambul por el Comité de Ministros del Consejo de Europa, el 7 de abril de 2011. Por lo tanto, el sexo, como circunstancia de discriminación, quedaría limitada a las cuestiones biológicas. $^{61}$

${ }^{55}$ LAURENZO (1996a), p. 245; también GARCÍA (2004), p. 68; RODRÍGUEZ (2007), p. 488; en contra BERNAL (1998), p. 43; por su parte, BORJA (1999), p. 257, considera que, si entendemos nación como un grupo humano con unos rasgos culturales, una lengua e historias comunes, entonces la nación se identifica con el concepto de etnia, de manera que debería admitirse el reconocimiento de este colectivo como titulares del derecho a no ser discriminado.

${ }^{56}$ Fundamento jurídico 5 de la Sentencia del Tribunal Constitucional 128/1987, de 16 de julio.

${ }^{57}$ Sentencia del Tribunal Constitucional 166/1988, de 26 de septiembre, reconoció el embarazo como un motivo de discriminación por razón de sexo.

Véase el Fundamento Jurídico $4^{\circ}$ de la Sentencia del Tribunal Constitucional 182/2005, de 4 de julio, en la que se recopila la doctrina del Tribunal Constitucional al respecto.

En relación con la evolución de la doctrina del Tribunal Constitucional, REY (2010), pp.77-110.

${ }^{58}$ Sirve de ejemplo la solución al caso del Imán de Fuengirola (Sentencia del Juzgado de lo Penal de 12 de enero de 2004). El artículo 510 contemplaba solo el sexo, dentro de su catálogo de circunstancias sospechosas de discriminación. Sin embargo, se consideró que el Imán era autor de un delito de provocación a la violencia por razón de sexo, por ejemplo, al "reclamar como requisitos del trabajo de la mujer que se amolde a su naturaleza, aptitudes y las predisposiciones innatas de ésta", aspectos vinculados con los prejuicios sociales. Hoy en día, se relacionarían con el género.

${ }^{59}$ Sobre los motivos para incorporar esta circunstancia, a pesar de no cubrir ninguna laguna legal GÓMEZ (2016), pp. 18-25.

${ }^{60}$ Motivo XXII en relación con su incorporación al artículo 22.4 del Código Penal.

${ }^{61}$ El Tribunal Supremo ha entendido en Sentencia 420/2018, de 25 de septiembre, que "La agravante por razones de género se caracteriza, $[. .$.$] porque el hecho debe ser cometido en el ámbito de las relaciones de$ 


\section{TAPIA, Patricia: "El discurso de odio del art. 510.1.a) del Código Penal español: la ideología como un Caballo de Troya entre las circunstancias sospechosas de discriminación".}

Esta división debería acabar con una incongruencia presente en nuestro ordenamiento desde que se aprobó la Ley Orgánica 1/2004, de 28 de diciembre, de Medidas de Protección Integral contra la Violencia de Género, momento a partir del cual se identifica el sexo con los elementos biológicos de $\operatorname{los}$ sujetos, ${ }^{62}$ mientras que con género se engloban aquellas facultades, virtudes o defectos que se atribuyen a un determinado sexo como resultado de los prejuicios sociales. Sin embargo, la incorporación de las razones de género no se ha realizado de forma generalizada a todos los delitos antidiscriminatorios. La reforma de 2015 solo la contempla en la circunstancia agravante genérica antidiscriminatoria del artículo 22.4 y en los delitos previstos en los artículos 510, 511, 512 y 607 bis del Código Penal. ${ }^{63}$

Esta falta de sintonía en los diferentes catálogos de circunstancias sospechosas de discriminación obliga a realizar interpretaciones inimaginables antes de la reforma. Debe tenerse en cuenta que, si en la circunstancia agravante genérica antidiscriminatoria se diferencia entre sexo y género, la referencia a una sola de estas circunstancias en otro catálogo obliga a realizar una interpretación sistemática. Así, en los preceptos en los que no se hace referencia a las razones de género, solo se tutelará a la mujer frente a actos discriminatorios vinculados con cuestiones biológicas, cosa que antes de la reforma no ocurría, ni creemos que sea el propósito del legislador. Si bien es cierto que, en todo este tiempo, no ha subsanado el error.

\subsection{Orientación o identidad sexual}

La orientación sexual también se incorpora por primera vez al catálogo de circunstancias sospechosas de discriminación con la aprobación del Código Penal de 1995. Con ella, se pretende proteger a todos los colectivos susceptibles de ser víctima de segregación social, aunque no tuvieran una larga tradición histórica como grupo unido. En concreto, los homosexuales, quienes a lo largo del siglo XX fueron forjando su propia identidad, $\mathrm{y}$ sufrieron la persecución y represión franquista, pero también se protegía a través de esta circunstancia a las personas transexuales y transgénero. ${ }^{64}$

La identidad sexual se incorporó mediante la reforma del Código Penal operada a través de la Ley Orgánica 5/2010, de 22 de junio. La referencia a esta nueva circunstancia obliga a otorgarle un contenido específico el cual se extrae del de orientación sexual. De este modo, con orientación sexual se tutelará al colectivo de personas homosexuales o bisexuales,

\footnotetext{
pareja. lo que le atribuye una evidente especificidad", con lo que no estamos de acuerdo. Es cierto que en el ordenamiento español se ha vinculado el género con la violencia dentro de la pareja, lo cual tiene sentido si se considera al Derecho Penal como aquella herramienta jurídica a la que se debe acudir en último lugar y solo en los casos considerados más graves. Pero la asociación género-pareja está más que superada en la actualidad en el ámbito doctrinal e, incluso, en el social.

Con posterioridad, se ha cambiado el criterio: Sentencia del Tribunal Supremo 565/2018, de 19 de noviembre o Sentencia del Tribunal Supremo 99/2019, de 26 de febrero. Sobre este cambio GUTIÉRREZ (2020), pp. 308 y ss.

62 AGUILAR (2015), pp. 56-57 advierte que debe considerarse también al colectivo de las personas intersexuales.

${ }^{63}$ Sorprendentemente, no se alude al género en el delito de discriminación laboral. TAPIA (2019), pp. 1-26.

${ }^{64}$ Sobre la posición de especial desventaja en la que se encuentra este colectivo, MARTíN (2019), pp. 12 y ss.
} 


\section{Polít. Crim. Vol. 16, № 31 (Junio 2021), Art. 11, pp. 284-320 [http://politcrim.com/wp-content/uploads/2021/07/Vol16N31A11.pdf]}

realizando una interpretación restrictiva, mientras que con identidad sexual se alude a aquellas situaciones en las que el sexo biológico de una persona no se corresponde con su identidad sexual, con el sexo que sienten, por lo que se someten a una reasignación sexual mediante una operación quirúrgica, de manera que se tutela a las personas transexuales frente a actos discriminatorios.

El problema está en que, igual que ha ocurrido con las razones de género, la identidad sexual no se contempla en todos los delitos antidiscriminatorios. En su caso, solo se ha incorporado a los catálogos de la circunstancia agravante antidiscriminatoria del artículo 22.4 y en los distintos tipos comprendidos en el artículo 510 del Código Penal. En la práctica se genera una desprotección de los colectivos que se tutelan a través de la identidad sexual en los delitos donde no se alude a esta circunstancia de forma específica, cosa que antes de la reforma no ocurría porque quedaban comprendidos con la orientación sexual. ${ }^{65}$

\subsection{Situación familiar}

La situación familiar como circunstancia sospechosa de discriminación no es fácil de delimitar. García considera que se alude al estado civil, las vinculaciones afectivas o relaciones de hecho, así como el tipo de filiación. ${ }^{66}$ De este modo, la discriminación iría dirigida, por ejemplo, a madres solteras, personas divorciadas, personas sin uno o ningún progenitor reconocido, etc. Situaciones, todas ellas, que podían ser objeto de discriminación en una época distinta a la actual. O que, quizá, todavía pueden implicar un trato de discriminación indirecta en el ámbito civil, administrativo o incluso laboral, pero que no se contempla de forma dolosa y con relevancia penal. Desde luego que no es un colectivo minusvalorado o situado en una posición de marginación dentro de la sociedad.

Por su parte, Rodríguez considera extensible esta causa a los supuestos en los que un miembro de la familia es discriminado porque uno de sus miembros ostenta alguna de las "características personales o sociales contempladas expresamente en el Código"67. Así, sería el caso de la discriminación a una persona porque su hijo o hija es transexual, o quien es discriminado porque sus progenitores son del mismo sexo. Entendemos que esto tiene sentido dentro de los delitos antidiscriminatorios.

\subsection{Enfermedad o discapacidad}

Hasta la aprobación de la Ley Orgánica 1/2015, de 30 de marzo, en todos los catálogos de los delitos antidiscriminatorios se aludía a enfermedad y minusvalía. Ambas circunstancias se incorporan de manera novedosa al Código Penal de $1995 .^{68} \mathrm{La}$ sustitución del término minusvalía por discapacidad se justifica en la Exposición de Motivos de la Ley, donde se reconoce que los términos de minusvalía o incapaces, utilizados en el texto punitivo, se han

\footnotetext{
${ }^{65}$ Sobre los problemas que pueden derivarse de esto, nos pronunciamos en TAPIA (2015), pp. 183-194.

${ }^{66}$ GARCÍA (2004), p. 73

${ }^{67}$ RODRÍGUEZ (2007), p. 531

${ }^{68}$ En un principio se discutió sobre la necesidad de aludir a la minusvalía junto a la enfermedad. BERNAL (1998), p. 46. A favor de la diferenciación MACHADO (2002), p. 234; FERNÁNDEZ (2009), p. 31. También, Sentencia del Tribunal Supremo de 22 de enero de 2008.
} 


\section{TAPIA, Patricia: "El discurso de odio del art. 510.1.a) del Código Penal español: la ideología como un Caballo de Troya entre las circunstancias sospechosas de discriminación".}

superado "desde la aprobación de la Ley 51/2003, de 2 de diciembre, de igualdad de oportunidades, no discriminación y accesibilidad universal de las personas con discapacidad, y que debe sustituirse por los términos más adecuados de "discapacidad" y de "persona con discapacidad necesitada de una especial protección"”. Asimismo, se trata de adaptar la terminología a la Convención Internacional sobre los Derechos de las Personas con Discapacidad, hecha en Nueva York el 13 de diciembre de 2006, que pretende prevenir las conductas discriminatorias que puedan impedirles el disfrute de sus derechos en igualdad de condiciones.

Con la referencia a enfermedad no se tutela a quienes cuentan con cualquier enfermedad, ${ }^{69}$ sino que debe ser una enfermedad susceptible de generar rechazo, situar en una posición de desventaja o, incluso, marginación dentro de la sociedad. ${ }^{70} \mathrm{Su}$ incorporación se produjo pensando, especialmente, en las personas enfermas de SIDA o portadoras del virus $\mathrm{VIH}^{71}$. Hoy, ambas circunstancias, en países como España han perdido esta condición marginal, pero debe recordarse que en las décadas de los ochenta y noventa, especialmente, la rápida propagación de la enfermedad y el desconocimiento inicial de la forma de contagio, provocaron conductas de rechazo. No obstante, el legislador, creemos que, de manera acertada, optó por una fórmula genérica, "enfermedad", en vez de la referencia explícita al SIDA y al VIH, de manera que tuvieran cabida también otras enfermedades como puede ser la hepatitis. Lo necesario es que, tal y como establece el Tribunal Constitucional, la enfermedad conlleve una distinción de trato que carezca de justificación objetiva y razonable. ${ }^{72}$

En lo que a la discapacidad se refiere, el artículo 25 del Código Penal español establece qué se debe entender por ella en el ámbito penal. En el precepto se determina que, con discapacidad, se alude a "aquella situación en que se encuentra una persona con deficiencias físicas, mentales, intelectuales o sensoriales de carácter permanente que, al interactuar con diversas barreras, puedan limitar o impedir su participación plena y efectiva en la sociedad, en igualdad de condiciones con las demás".

Señalado lo anterior, sin embargo, debemos advertir una vez más ${ }^{73}$ que la tutela de las personas con discapacidad y de las personas que cuentan con alguna enfermedad susceptible de discriminación, se realiza de modo diferente a los demás colectivos. Basta con repasar el catálogo de circunstancias sospechosas de discriminación para advertir que, salvo en la referencia a estas dos circunstancias, las demás se refieren de manera neutra, sin identificar directamente al colectivo al que se pretende tutelar. Mientras que en el caso de la enfermedad y la discapacidad se manifiesta explícitamente. Esto tiene sentido solo si reconocemos que tanto las personas con discapacidad como quienes padecen una enfermedad susceptible de

${ }^{69}$ Defienden una interpretación restrictiva del concepto de enfermedad como causa de discriminación LAURENZO (1996b), p. 247; MACHADO (2002), p. 233.

${ }^{70}$ BERNAL (1998), p. 45, alaba la decisión del legislador de optar por la expresión “"“enfermedad” lo suficientemente amplia para comprender no sólo los supuestos de discriminación en casos del SIDA, sino cualquier otra discriminación por causa de otra enfermedad distinta"; GARCÍA (2004), p. 75.

${ }^{71}$ Sobre la justificación de esta circunstancia CONDE-PUMPIDO (1996), p. 307.

${ }^{72}$ Fundamento Jurídico $3^{\circ}$ de la Sentencia del Tribunal Constitucional 34/1981, de 10 de noviembre.

${ }^{73}$ Así lo hacemos cada vez que tenemos oportunidad: TAPIA (2014), pp. 243-244; TAPIA (2017), p. 369. 


\section{Polít. Crim. Vol. 16, № 31 (Junio 2021), Art. 11, pp. 284-320 [http://politcrim.com/wp-content/uploads/2021/07/Vol16N31A11.pdf]}

trato discriminatorio, son considerados ciudadanos de segunda. Se asume su posición de desventaja o marginación, incluso, por la propia ley. Entendemos que el primer paso para cambiar esto es la sustitución de estos términos por salud y capacidad.

\subsection{La ideología como caballo de Troya entre las circunstancias sospechosas de discriminación}

Como el propio título de este trabajo advierte, y este subepígrafe ratifica, entendemos que la ideología requiere una especial atención en el ámbito de los denominados delitos de odio en general y de los delitos de discurso de odio en particular. Y esto porque a través de la ideología se pretende calificar como delito de discurso de odio cualquier expresión hiriente, ofensiva o de dudoso humor.

Si realizamos un mínimo recordatorio, en la incorporación de los delitos antidiscriminatorios al ordenamiento jurídico penal español, la ideología como circunstancia sospechosa de discriminación, se ha venido considerando en agresiones de grupos de extrema derecha frente a quienes podría calificarse de adversarios, es decir, una persona de extrema izquierda. ${ }^{74} \mathrm{El}$ primer caso en el que se aplicó, o al menos no hemos encontrado noticia de otro anterior, fue en el denominado caso de "Carlos Palomino", ${ }^{75}$ mediante la agravante genérica antidiscriminatoria del artículo 22.4 del Código Penal.

Sin embargo, en los últimos tiempos, se ha reclamado su aplicación en otros ámbitos, entre los que destacan los insultos dirigidos contra los toreros en las redes sociales, claro ejemplo el de Víctor Barrios o el niño Adrián ${ }^{76}$ en la quema del retrato de los Monarcas hacia abajo tras la manifestación antimonárquica celebrada en Gerona, ${ }^{77} \mathrm{o}$ en relación con los miembros de los Cuerpos y Fuerzas de Seguridad del Estado. Esto se defiende argumentando que se trata de conductas que implican un odio hacia estos colectivos (si es que se puede utilizar el término colectivo en relación con toreros, Monarcas y miembros de los Cuerpos y Fuerzas de Seguridad del Estado) y también, defendiendo que las circunstancias previstas en el catálogo de los delitos de odio o delitos antidiscriminatorios son bidireccionales y no unidireccionales. Bajo nuestro punto de vista, tal y como advierte Landa, con independencia del fallo condenatorio o absolutorio, la mera existencia de estos casos hace "constar una orientación interpretativa de los tipos penales anti-odio y, en particular, del artículo $510 \mathrm{CP}$ como un precepto no tanto de protección de colectivos o minorías más o menos vulnerables sino de colectivos muy ligados al ejercicio del poder institucional (en particular, de autoridades o funcionarios públicos, tales como alcaldes, policías nacionales, guardias civiles...)". ${ }^{78}$

\footnotetext{
${ }^{74}$ GORJÓN (2019), pp. 234-235 llama la atención sobre que la agravante genérica antidiscriminatoria "se aplica sobre todo a sujetos de extrema derecha y no tanto a sujetos de ideología de extrema izquierda, puesto que este pensamiento ha sido históricamente vinculado al terrorismo, a la ideología anarquista, etc."

${ }^{75}$ Sentencia del Tribunal Supremo 360/2010, de 15 de abril.

${ }^{76} \mathrm{Al}$ respecto, MIRÓ (2017), p. 58: "una interpretación tal que entendiera que este tipo de manifestaciones entran dentro de la categoría de la motivación ideológica supondrían una ampliación de los márgenes punitivos de este y otros preceptos que no se corresponde con las necesidades de intervención penal en este ámbito."

${ }^{77}$ Sentencia del Tribunal Europeo de Derechos Humanos 2018/27, de 13 de marzo.

${ }^{78}$ LANDA (2018), p. 102.
} 


\section{TAPIA, Patricia: "El discurso de odio del art. 510.1.a) del Código Penal español: la ideología como un Caballo de Troya entre las circunstancias sospechosas de discriminación".}

Precisamente es en esta línea donde, entendemos, se desarrolla la polémica más reciente en torno a la ideología y en la que han participado nuestros Tribunales. Nos estamos refiriendo al denominado caso de Alsasua. En este no se pide la aplicación del artículo 510.1 pero sí que se califiquen los hechos con la agravante genérica antidiscriminatoria por motivos ideológicos, como ocurrió en el citado caso de Carlos Palomino. Lo relevante es que permite, igualmente, plantear el debate en torno al contenido de esta circunstancia sospechosa de discriminación.

Brevemente, los hechos se produjeron en octubre de 2016 en la localidad navarra de Alsasua. Un Teniente y un Sargento de la Guardia Civil, fuera de servicio, entraron con sus parejas en un bar de la localidad. En un momento determinado, un grupo de personas que se encontraba en el bar, los rodeó y empezó a proferir expresiones como "picoletos", "esto os pasa por venir aquí, os vamos a matar por ser Guardias Civiles...”, y expresiones similares, a la vez que eran agredidos con golpes, puñetazos y patadas.

Conforme al relato de hechos probados, la Audiencia Nacional, en Sentencia 2023/2018, de 1 de junio, condenó a los acusados por atentado a los Agentes de la autoridad en concurso ideal con delito de lesiones, con la concurrencia de la agravante de discriminación, entre otros delitos. En la Sentencia 2/2019 de la Audiencia Nacional, de 7 de marzo, se ratificó el argumento dado en la Sentencia anterior, entendiendo que es la "animadversión e intolerancia de los acusados hacia la Guardia Civil [...] lo que provoca de forma directa la discriminación hacia ese grupo de personas pertenecientes a dicho estamento, discriminación que llega hasta el punto concreto de que esas personas y sus novias no puedan moverse con libertad por la localidad de Alsasua [...]".

No obstante, el Tribunal Supremo, en Sentencia 3124/2019, de 9 de octubre, ha corregido la interpretación anterior $\mathrm{y}$ ha considerado que no podía aplicarse la agravante antidiscriminatoria genérica por razón de ideología. Para ello desarrolla varios argumentos.

En primer lugar, se advierte que la circunstancia agravante debe referirse a la víctima ${ }^{79}$, por lo que será necesario que la víctima presente una ideología que pueda ser "aprovechada por el sujeto activo para imponer un comportamiento lesivo fundado en una ideología que opera como mecanismo de discriminación". En los hechos probados no se identifica la ideología de las víctimas y "la situación fáctica de pertenencia al instituto armado policial ya ha sido tenida en cuenta por el tribunal de instancia aplicando la calificación de atentado por el hecho cometido". 80

\footnotetext{
${ }^{79}$ Este es el argumento esgrimido en el Auto del Tribunal Superior de Justicia de Cataluña (Sala de lo Civil y de lo Penal, Sección $1^{\text {a }}$ ), 72/2018, de 28 de junio, para inadmitir la querella presentada por el Ministerio Fiscal contra un Diputado del Parlament de Catalunya por un "delito de odio" del artículo 510 por haber publicado entre los días 2 y 3 de octubre de 2017 en Twitter instando a que se expulsase de los hoteles a los miembros de la Policía Nacional y de la Guardia Civil que esos días se encontraban alojados allí.

No obstante, sí se admitió la querella en Auto del Juzgado de Instrucción de Reus (Provincia de Tarragona) de 10 diciembre de 2018, por unos hechos similares. En este caso se consideró que debía admitirse la querella por un "delito de odio" porque las manifestaciones no se dirigían contra la policía, sino que eran contra la policía española. Por lo que lo relevante es el origen nacional.

${ }^{80}$ Fundamento jurídico quinto de la Sentencia del Tribunal Supremo 3124/2019, de 9 de octubre.
} 


\section{Polít. Crim. Vol. 16, № 31 (Junio 2021), Art. 11, pp. 284-320 [http://politcrim.com/wp-content/uploads/2021/07/Vol16N31A11.pdf]}

Por otro lado, el Tribunal Supremo argumenta que el contenido de la circunstancia agravatoria debe vincularse a situaciones necesitadas de especial protección. Y lo hace apoyándose en la tradición histórico-legislativa de la discriminación en nuestro ordenamiento jurídico. En este sentido, entiende el Tribunal Supremo que "es difícil argumentar una consideración de la Guardia Civil como colectivo vulnerable sin desnaturalizar la finalidad del precepto". Sigue así el Tribunal Supremo lo establecido por el Tribunal Europeo de Derechos Humanos en la Sentencia sobre el caso Sacca Terentyev c. Rusia, de 28 de agosto de 2018, en la que se rechaza que la policía sea una minoría o colectivo desprotegido. ${ }^{81}$ Finalmente, recuerda el Tribunal Supremo que "En todo hecho delictivo, ciertamente se plantea un contexto de enfrentamiento donde pueden emerger sentimientos de odio, ira o rabia, y no por ello la punición del delito precisa una especial valoración jurídica que se traslade a la agravación en el reproche penal, pese a existir esa situación de odio, ira, rabia o venganza" 82 .

Sin embargo, el magistrado Magro Servet formuló un voto particular, al que se adhiere del Moral García, defendiendo la aplicación de la circunstancia agravante. Entienden los magistrados que la referencia en los hechos probados a la "animadversión por esa presencia de las víctimas en su localidad y por su pertenencia a la guardia civil" supone reconocer que las víctimas representan un colectivo, "que es institución del Estado español, sobre el que giraba su espíritu por los condenados un sentimiento de odio como tal colectivo, siendo tal significación la ideología que se representaba por los agentes autores, como la propia de las víctimas a que se refiere el art. 22.4 CP". Se argumenta, también, que no resulta incompatible la calificación de los hechos como delito de atentado con la agravante de discriminación, ya que "la configuración del delito de atentado dimana del dato objetivo de agredir a un agente de la autoridad como elemento objetivo del injusto, pero no existe igualdad de fundamento en la aplicación de la agravante de discriminación del art. 22.4 CP que se enraíza en un fundamento de naturaleza subjetiva" y tampoco se infringe el principio de inherencia porque "No se recoge en la tipificación del atentado los actos de carácter discriminatorio". Entienden estos magistrados que "De lo que se trata es de llevar a cabo un ataque a una institución representativa del Estado español y su odio por su presencia en la zona geográfica con un deseo de desaparición del lugar, que es lo que motiva el ataque".

De este modo, defienden que "la idea que patrocina la agravante es sancionar las acciones y sentimientos de "exclusión social" que llevan aparejada una discriminación a otras personas por considerarlas diferentes a lo que el sujeto autor del delito considera cuáles deben ser los patrones que deben seguir las personas para poder convivir con ellos en una localidad". Continúa argumentando que "el derecho penal debe sancionar con mayor dureza las denominadas conductas excluyentes, enraizadas en la idea que tiene el sujeto del delito de quienes son las personas que ellos permiten vivir a su lado en un edificio, en una localidad, en un puesto de trabajo, en dependencias escolares, etc [...] la agresión se produce, precisamente, $[. .$.$] por pertenecer las víctimas a la guardia civil y a sus novias, por ser novias$ de guardias civiles, lo que supone una evidente, palpable y absolutamente rechazable

\footnotetext{
${ }^{81}$ Así, ANDEREZ (2019), pp. 511-538.

${ }^{82}$ Fundamento jurídico quinto de la Sentencia del Tribunal Supremo 3124/2019, de 9 de octubre.
} 


\section{TAPIA, Patricia: "El discurso de odio del art. 510.1.a) del Código Penal español: la ideología como un Caballo de Troya entre las circunstancias sospechosas de discriminación".}

discriminación por la pertenencia de las víctimas a las Fuerzas y Cuerpos de Seguridad del Estado".

En definitiva, entienden los Magistrados que "no se trata de una discriminación por razón de pertenencia a una profesión en concreto, como es la de guardia civil, sino a lo que ello representa en su contexto o contorno de institución del Estado, cuya presencia desean desaparezca de su entorno geográfico [...] Y ello tiene su engarce en la "ideología" para referirse a la víctima, porque por tal sí podemos tratar la pertenencia de las víctimas a la Institución del Estado, por lo que ello representa y en el ámbito de odio que se reflejaba en la conducta que desde un primer momento los condenados llevaron a cabo, al preguntarles si eran policías y tratarles con absoluto odio y desprecio".

En nuestro caso, nos situamos con el sentir mayoritario del Tribunal Supremo. Es cierto que la calificación de los hechos como delito de atentado no impide la consideración de la circunstancia agravante genérica antidiscriminatoria. Resulta innegable que el delito de atentado no contempla un elemento discriminador. Sin embargo, el problema sigue estando en la determinación del sujeto pasivo. Bajo nuestro punto de vista, si los hechos se hubieran producido porque las víctimas formaban parte de un grupo étnico susceptible de ser discriminado, por ejemplo, se podría haber valorado el delito de atentado con aplicación del 22.4 del Código Penal, sin ninguna dificultad. Pero entendemos que, por mucho que en una localidad concreta el gremio de Guardias Civiles sea visto con desprecio, no cuenta con las características necesarias para calificarlos como minoría o como colectivos susceptibles de ser discriminados. ${ }^{83}$ Hacer esto, solo puede llevar a desvirtuar la propia existencia de los delitos antidiscriminatorios permitiendo que, por ejemplo, se aplicase la agravante genérica antidiscriminatoria por motivos ideológicos en robos de viviendas de sujetos acaudalados, si se demostrase que los autores seleccionan a sus objetivos por la animadversión que sienten hacia aquellos que disfrutan de una vida acomodada. Colectivo este que nada tiene que ver con aquellos a los que se trata de proteger frente a conductas discriminatorias.

Somos conscientes de lo polémica de nuestra posición. Así lo demuestran la citada Circular de la Fiscalía General del Estado 7/2019 o el Informe de delimitación conceptual en materia de delitos de odio, encargado a Díaz por la Comisión de Seguimiento del Convenio de colaboración y cooperación Interinstitucional contra el racismo, la xenofobia y otras formas de intolerancia.

En el Informe, Díaz afirma que la referencia a la ideología comprende "cualquier creencia en una determinada forma de organización política del Estado: ya sea con el mantenimiento del actual Estado español como monarquía parlamentaria, su transformación en un Estado

\footnotetext{
${ }^{83}$ En este sentido, BILBAO (2018), p. 17; LAURENZO (2018), p. 16.

En relación a los mensajes MIRÓ (2017), p. 47 advierte que "También conllevan una expresión de intolerancia aquellos mensajes que se dirigen hacia el grupo "los catalanes" o hacia los que defienden "el toreo". En estos casos, sin embargo, la carga ofensiva, por discriminatoria, es diferente, particularmente al no constituir grupos que hayan sufrido en el pasado actos de discriminación de sus derechos, siendo más que discutible, en el último de los casos, incluso que se trate de un colectivo sobre el que existe una posibilidad futura de ser objeto de discriminación."
} 
totalitario, su mutación en República federal, su disolución y creación de otros Estados independientes, o cualesquiera otras formas de organización política" ${ }^{84}$ Por su parte, la Circular acepta esta definición y la amplía, considerando que también comprende las creencias relacionadas con el "sistema social, económico e incluso al cultural" (p. 28).

En principio, podríamos estar de acuerdo en la definición. Pero esta debe considerarse como lo que es: una definición neutra de la circunstancia en la que no se delimita al colectivo titular del bien jurídico. Bajo nuestro punto de vista, seguidamente, es necesario delimitar al colectivo que se encuentra en una posición de inferioridad o vulnerabilidad dentro de la sociedad. Y esto no se hace en ninguno de los dos documentos. Prueba de ello es que, tanto en el Informe de delimitación conceptual en materia de delitos de odio, como en la Circular 7/2019 se admite la sanción mediante el artículo 510.1.a del Código Penal de discursos de odio contra la ideología neonazi. ${ }^{85}$

Como ya adelantamos sobre nuestra posición respecto al bien jurídico, el sujeto pasivo deberá formar parte de un colectivo que integre una minoría, entendida desde la "soledad" en la que se encuentra un determinado grupo por ostentar alguna de las circunstancias previstas en el catálogo del precepto, y que lo sitúa en una posición de inferioridad o incluso marginación dentro de la sociedad. ${ }^{86} \mathrm{Si}$ no encontramos justificación para incorporar a los toreros, miembros de las fuerzas y cuerpos de seguridad del Estado o los Monarcas, por no constituir un grupo tradicionalmente situado en una posición de marginación, o de desventaja dentro de la sociedad, pretender proteger especialmente al colectivo de ideología nazi nos resulta un absoluto despropósito. Los delitos antidiscriminatorios surgen y tienen su máximo desarrollo precisamente como respuesta a esa ideología, ¿qué sentido tiene brindarle una especial protección bajo el fundamento de constituir un colectivo que parte de una posición de desventaja? Dicha desventaja, si es que existiera, debería ser algo de lo que enorgullecernos como sociedad. Obviamente no significa que el ataque a personas de ideología nazi deba resultar impune. Pero, desde luego, no puede integrar un delito de discurso de odio, en el sentido de los discursos discriminatorios racistas, xenófobos u homófobos.

Teniendo en cuenta este argumento, tampoco sería admisible su aplicación en aquellos casos en los que la agresión parte de alguien de extrema derecha frente a otro de extrema izquierda, como ocurrió en el caso de Carlos Palomino. Debemos reconocer que, hasta muy recientemente, no nos habíamos planteado la inadecuación del artículo 22.4 por razón de ideología en este caso o en otros similares. Sin embargo, la obligación de profundizar en esta circunstancia sospechosa de discriminación ante las continuas demandas de ampliación, nos ha llevado a una reflexión que deja fuera también estos supuestos. Entendemos que un grupo de ideología antifascista $o$, al contrario, de ideología fascista no puede considerarse un colectivo objeto de discriminación ${ }^{87}$ porque, como grupo, como colectivo, no se encuentra en una posición de marginación o desventaja dentro de la sociedad.

\footnotetext{
${ }^{84}$ DÍAZ (2018), p. 58.

${ }^{85}$ Circular 7/2019, p. 23; Informe, p. 58.

${ }^{86}$ PÉREZ et al. (1993), p. 65; MARKEFKA, (1990), p. 13 y ss.; ROTTLEUTHNER y MAHLMANN (2011), p. 26.

${ }^{87}$ Como hemos indicado, no es esta la posición jurisprudencial. Sentencia del Tribunal Supremo 1037/2013, de 27 de diciembre, donde se admite la concurrencia de la agravante genérica antidiscriminatoria por razón de
} 


\section{TAPIA, Patricia: "El discurso de odio del art. 510.1.a) del Código Penal español: la ideología como un Caballo de Troya entre las circunstancias sospechosas de discriminación".}

Es cierto que la elección de Carlos Palomino como víctima solo tenía relevancia para su agresor por su ideología, pero la realidad es que la conducta del agresor no perpetúa una posición de desventaja o de marginación dentro de la sociedad de los colectivos antifascistas. Es decir, no lesiona la dimensión colectiva del bien jurídico no ser discriminado por lo que, entendemos, no debería haberse aplicado la agravante genérica.

Por todo lo anterior, consideramos que la ideología a la que se alude en el ámbito de la discriminación debe restringirse al máximo, siguiendo los Tratados y Convenios Internacionales donde se vincula con el racismo y la xenofobia. Ideologías que, por otro lado, estarían comprendidas en las circunstancias de raza, etnia y origen ${ }^{88}$. De lo contrario, corremos el riesgo de convertir la ideología en un caballo de Troya que permita calificar cualquier conducta realizada con animadversión en un delito de odio o cualquier manifestación revestida de animadversión, en un delito de discurso de odio.

\subsection{Religión y creencias}

Junto a la ideología se sitúan la religión o creencias. Con estas tres circunstancias se tutela la libertad de pensamiento, distinguiendo diferentes parcelas de protección. Si bien, no siempre es sencillo determinar el alcance de cada una de ellas. Es por esto que, en general, suele referirse a la libertad ideológica y, en tal caso, a la religión.

$\mathrm{Al}$ respecto, debemos señalar que la religión es una de las circunstancias que se tutelan en el ordenamiento jurídico penal español más allá del ámbito de la discriminación. En este sentido, la Sección $2^{a}$ del Capítulo IV del Título XXI dedicado a los delitos contra la Constitución, se ocupa específicamente de los delitos contra la libertad de conciencia, los sentimientos religiosos y el respeto a los difuntos (artículos 522-526 del Código Penal). Con independencia de los debates o críticas doctrinales sobre la idoneidad de mantener estos delitos dentro de un Estado democrático de origen liberal e ilustrado ${ }^{89}$, en la actualidad existe cierto consenso en considerar que los bienes jurídicos protegidos serán la libertad de obrar y de motivación (artículos 522 y 523) y el honor (artículos 524-526) ${ }^{90}$. Desde esta perspectiva, a través de estos preceptos, se tutelaría la libertad de obrar y de motivación, así como el honor de cualquier sujeto individual en el ámbito de sus convicciones religiosas.

\footnotetext{
ideología ante un caso en el que un grupo de extrema izquierda acuerda ir al bar donde se encontraba la víctima, que se autodefinía de ideología franquista-falangista y le propinó una paliza. Se entiende que "la razón del acometimiento fue la ideología de la víctima, por la vinculación contraria de los agresores".

${ }^{88}$ Entiende LANDA (2018), p. 116, que "Debería plantearse si no sería conveniente que los motivos ideológicos tuvieran una consideración incluso más restrictiva que otro tipo de motivaciones -racismo, xenofobia...- a la hora de otorgar relevancia penal a discursos en dicho contexto.", si bien no se concreta la necesidad de delimitar los colectivos.

${ }^{89}$ Véase, CUERDA (2019), pp. 672 y ss.; LAURENZO (2018), p. 1289 quien advierte cómo el necesario pluralismo ideológico-religioso para tutelar la libertad religiosa individual, se resquebraja "a raíz de la fuerte corriente de islamofobia que invadió todo el mundo occidental después de los atentados del 11 de septiembre de 2001"; en una línea similar BAGES (2019), pp. 251 y ss.

${ }^{90}$ En este sentido, BAGES (2019), p. 21, aunque con algunos matices, que no vienen al caso, se posiciona con la doctrina moderna.
} 


\section{Polít. Crim. Vol. 16, № 31 (Junio 2021), Art. 11, pp. 284-320 [http://politcrim.com/wp-content/uploads/2021/07/Vol16N31A11.pdf]}

Pero entendemos que este no es el escenario de los delitos de odio o delitos de discurso de odio (para nosotros, delitos antidiscriminatorios). Como se ha repetido en las páginas anteriores, en estos delitos el sujeto pasivo debe pertenecer a un colectivo o minoría caracterizado por alguna de las circunstancias sospechosas de discriminación previstas en el catálogo del precepto concreto. En el caso de la religión, deberá vincularse con algún colectivo o minoría que profesa una religión que lo sitúa en una posición de desventaja o inferioridad dentro de la sociedad, impidiendo acceder en igualdad de condiciones a las oportunidades generales de cualquier persona perteneciente al colectivo "modelo". En este sentido, tal y como advierte Laurenzo, "Solo cuando la religión se asocia a estereotipos negativos que sitúan a sus creyentes en una posición de marginación o rechazo social surge la necesidad de una tutela adicional del Derecho penal para prevenir agresiones (físicas o no) a sus derechos fundamentales. Unas agresiones que tienen su origen en el menosprecio hacia el colectivo discriminado y poseen, por ello, un potencial lesivo que no existe o es incomparablemente menor cuando se trata de religiones mayoritarias". ${ }^{91}$ Por lo tanto, en nuestra sociedad, no tendría sentido hablar de discriminación respecto de los que profesan la religión católica, pero sí podría considerarse determinadas prácticas frente a la religión musulmana.

\section{La acción típica}

Delimitado el bien jurídico y el sujeto pasivo, corresponde detenernos en la acción típica. Establece el apartado a) del artículo 510.1 que se sanciona penalmente la conducta de quienes "públicamente fomenten, promuevan o inciten directa o indirectamente al odio, hostilidad, discriminación o violencia".

Se trata de una descripción tan amplia de la conducta prohibida que tiene cabida, prácticamente, todo. ${ }^{92}$ Pensemos en el autobús de Hazte Oír que recorrió algunas ciudades españolas en el año 2017 con el mensaje "Los niños tienen pene. Las niñas tienen vulva. Que no te engañen", o la publicación en Twitter de mensajes como " 53 asesinadas por violencia de género machista en lo que va de año, pocas me parecen con la de putas que hay sueltas", junto con otros mensajes del estilo, por ejemplo: "Y 2015 finalizará con 56 asesinadas, no es una buena marca pero se hizo lo que se pudo, a ver si en 2016 doblamos esa cifra, gracias". ${ }^{93}$ Ambos supuestos fueron considerados en algún momento delito de discurso de odio, aunque con un recorrido jurisdiccional muy distinto. El caso del autobús de Hazte Oír fue archivado mientras que el del twittero se consideró constitutivo de un delito del artículo 510.1 del Código Penal, en Sentencia del Tribunal Supremo 72/2018, de 9 de febrero. Precisamente esta disparidad es la que nos ayudará a poner de manifiesto los problemas que plantea la redacción del precepto.

\footnotetext{
${ }^{91}$ LAURENZO (2018), p. 1300

${ }^{92}$ En este sentido, ALASTUEY (2016), p. 16 dirá que "la voluntad del legislador parece clara: su objetivo ha sido ampliar el ámbito de aplicación del precepto y evitar los posibles resquicios de interpretaciones restrictivas de su tenor literal.".

${ }^{93}$ Sentencia de la Audiencia Nacional 2/2017, de 26 de enero y STS72/2018, de 9 de febrero. Sobre este caso, puede verse el análisis de GORJÓN (2019), pp. 243-246.
} 


\section{TAPIA, Patricia: "El discurso de odio del art. 510.1.a) del Código Penal español: la ideología como un Caballo de Troya entre las circunstancias sospechosas de discriminación".}

El tipo exige publicidad. La publicidad es un requisito que pretende delimitar la conducta punible. Esto significa que no tendrán relevancia penal aquellas acciones que se circunscriban al ámbito privado o semiprivado, ya que pierde potencialidad incitadora. Esta publicidad, sin embargo, no comprende el uso de medios de comunicación social, internet o el uso de tecnologías de la información porque, en estos casos, estaríamos ante una modalidad agravada prevista en el apartado 3 del artículo 510. De este modo, en la era de las comunicaciones y de las redes sociales, su uso, que se correspondería con lo habitual, se convierte en modalidad agravada. En los ejemplos expuestos, el autobús de Hazte oír, obviamente, constituye un instrumento para dar publicidad a su mensaje y, en el segundo caso, debería considerarse una modalidad agravada por hacerlo a través de Twitter. Lo curioso es que, muy probablemente, el número de personas a las que llegó el mensaje del autobús es significativamente superior a los seguidores del sujeto que escribió los citados mensajes en su cuenta de Twitter. Volveremos a ello al referirnos a las modalidades agravadas.

El apartado a) del artículo 510.1 del Código Penal, después de exigir publicidad, describe distintas modalidades de ejecución asentadas en los verbos rectores de fomentar, promover o incitar. Con ellas se sustituye el anterior verbo "provocar", si bien, la modificación no ha sido precisamente aplaudida. Se critica que, aunque se acaba con la polémica referida a su relación con el artículo 18, resulta imposible distinguir entre fomentar, promover e incitar, como conductas que constituyen distintas formas de ejecución. Se trata de sinónimos que lo único que consiguen es propiciar mayores dudas interpretativas y de aplicabilidad. En los ejemplos planteados, el mensaje de Hazte Oír incita, promueve o fomenta que se obvie una realidad, y es que existen personas cuyo sexo biológico no se corresponde con su identidad sexual. Por su parte, el twittero banaliza la violencia de género y expresa un deseo de que haya más mujeres víctimas de esta lacra.

El incitar, promover o fomentar puede ser de manera directa o indirecta. Hasta la reforma de 2015 no se indicaba nada, por lo que se entendía que la provocación debía ser directa. Téngase en cuenta que, con independencia de que se considerase un acto preparatorio en la línea del artículo 18 del Código Penal o un delito autónomo, estamos hablando de un delito de peligro hipotético, por lo que su punibilidad debería ser restringida. Sin embargo, con la reforma de 30 de marzo de 2015, se permite explícitamente que la incitación sea directa o indirecta. El legislador lo justifica en la Sentencia del Tribunal Constitucional 235/2007, de 7 de noviembre, por la que se declaró inconstitucional la punibilidad de la negación del genocidio porque castigaba "la transmisión de ideas en sí misma considerada, sin exigir adicionalmente la lesión de otros bienes constitucionalmente protegidos", mientras que la justificación del genocidio, cumple con los estándares constitucionales en la medida que se interprete como "incitación indirecta" a la realización de un delito de genocidio.

Esta referencia a la incitación indirecta hace que el legislador penal la incorpore al artículo 510.1.a, como si de una obligación se tratase, cuando, en realidad, es una interpretación de mínimos para que la conducta sea punible conforme al marco constitucional. Pero es que, además, estamos con PORTILLA cuando advierte que "no se respeta la línea emprendida" por la citada Sentencia ya que la constitucionalidad de la incitación indirecta depende de que 


\section{Polít. Crim. Vol. 16, № 31 (Junio 2021), Art. 11, pp. 284-320 [http://politcrim.com/wp-content/uploads/2021/07/Vol16N31A11.pdf]}

vaya dirigida a la realización de un delito. Y esto no se contempla en el tipo ${ }^{94}$. Entendemos que la incitación indirecta supone un peligro abstracto del bien jurídico, mientras que, en el caso de la incitación directa, existe un riesgo más o menos inminente, pero sí real, de que se lesione el bien jurídico protegido o de que se materialicen los actos de violencia o discriminación a los que se incita ${ }^{95}$.

El problema está en que la previsión de fomentar, promover o incitar indirectamente abre un abanico de posibilidades excesivamente amplio. Coincidimos con Alastuey en que "la mayoría de las conductas típicas están muy lejos de representar un peligro mínimamente relevante para el mencionado bien jurídico". ${ }^{96}$ Siendo esto así, se permite que el autobús de Hazte Oír o las manifestaciones vertidas en Twitter banalizando la violencia de género puedan ser punibles.

A esto se le debe añadir que tal fomento, promoción o incitación deben ir dirigidos a generar odio, violencia, discriminación u hostilidad. Al respecto, estamos con De Vicente cuando advierte que "la intencionalidad no siempre es fácil de demostrar, especialmente cuando las observaciones tienen que ver de forma ostensible con hechos pretendidos o cuando se utiliza un lenguaje codificado". ${ }^{97}$ Pero es que, además, habrá que concretar qué significa incitar al odio, violencia, discriminación u hostilidad.

La determinación de la incitación a la discriminación o a la violencia no resulta especialmente difícil. Otra cosa es que sea discutible que la incitación a la discriminación sea una conducta delictiva y que la realización de ese acto discriminatorio no lo sea. Pero, en cualquier caso, podemos identificar la finalidad de la incitación. El problema estará en cómo determinar la posibilidad de crear un clima de odio y, lo que en el ámbito penal es más relevante, ¿cómo sancionar el intento de crear un clima de odio, si el odio es un sentimiento y los sentimientos no deben ser sancionados penalmente? El odio solo será relevante en la medida en que se manifieste de alguna manera. Podrá hacerlo a través de actos de discriminación o directamente de violencia por lo que la simple incitación al odio supone un paso previo a la incitación de la violencia o de la discriminación, muy alejado, por lo tanto, de la eventual lesión del bien jurídico. En general, la doctrina mayoritaria entiende, y ahí nos posicionamos también, que el fomento, promoción o incitación directa o indirecta al odio no consiguen proteger el bien jurídico sino que suponen la censura de opiniones, hechos, que podrían llegar a ser un acto preparatorio de la discriminación o de la violencia con motivo discriminatorio. ${ }^{98}$

La hostilidad, por su parte, se identifica con violencia por lo que resulta redundante, confusa e innecesaria su incorporación.

La Comisión Europea contra el Racismo y la Intolerancia, la denominada ECRI, ha establecido una serie de pautas o criterios que ayudan a delimitar la punibilidad del discurso de odio. En el Memorándum Explicativo de la Recomendación de Política General no 15

\footnotetext{
${ }^{94}$ PORTILLA (2015), p. 737.

${ }^{95}$ Véase DE VICENTE (2018), p. 131.

${ }^{96}$ ALASTUEY (2016), p. 19.

${ }^{97}$ DE VICENTE (2018), p. 123.

${ }^{98}$ PORTILLA (2017), p 95; MIRÓ (2017), p. 51
} 


\section{TAPIA, Patricia: "El discurso de odio del art. 510.1.a) del Código Penal español: la ideología como un Caballo de Troya entre las circunstancias sospechosas de discriminación".}

relativa a la lucha contra el discurso de odio, de 8 de diciembre de 2015 , se establece que la imposición de sanciones penales por el uso de discurso de odio debe limitarse a los casos más graves, es decir, a aquellos en los que quepa suponer razonablemente que va a tener efecto el discurso. ${ }^{99}$ Así, se establece que habrá que tener en cuenta: el contexto en el que se utiliza el discurso de odio, especialmente, si hay tensiones graves relacionadas con este discurso en la sociedad; la capacidad que tiene la persona que emplea el discurso de odio para ejercer la influencia sobre los demás, por ser un líder político, religioso o de la comunidad; la naturaleza y contundencia del lenguaje empleado, así por ejemplo, difusión de estereotipos negativos y estigmatizantes, uso de información engañosa; contexto de los comentarios, es decir, habrá que valorar si es un comentario aislado, si forma parte de un debate en el que se está utilizando un lenguaje similar; el medio utilizado, en el sentido de si puede provocar respuesta inmediata de la audiencia; y la naturaleza de la audiencia, es decir, si es posible que se mezcle con actos de violencia, intimidación, hostilidad o discriminación. ${ }^{100}$

Teniendo en cuenta lo anterior, si volvemos a los ejemplos señalados al principio, una interpretación literal del precepto permitiría que tanto el mensaje del autobús de Hazte Oír como los mensajes del twittero tuvieran cabida dentro del tipo porque ambos incitan, al menos de manera indirecta, al odio y/o discriminación de las personas transgénero, en un caso, y de las mujeres, en el otro. No obstante, siguiendo las Recomendaciones de la ECRI la conclusión sería distinta.

En relación con el mensaje del autobús Hazte Oír, nos cuesta valorar si se realiza en un contexto de tensiones graves relacionadas con este discurso en la sociedad. Si bien es cierto que el colectivo denominado trans es uno de los que se encuentra en una posición de clara desventaja social, rozando en un número elevado de situaciones la marginación, resulta también innegable que en los últimos tiempos ha ganado visibilidad gracias a la labor de asociaciones como Chrysallis o la fundación Daniela. Esto ha facilitado una mayor concienciación social sobre la necesidad de tutela y reconocimiento de este colectivo. En lo que al emisor del mensaje se refiere, podría considerarse que cuenta con cierta capacidad de influencia. Se trata de una asociación declarada de utilidad pública, en ese momento, cuya finalidad, según ellos mismos dicen, es defender la vida humana, la libertad de educación y la familia, desde una perspectiva ultracatólica (esto lo añadimos nosotros), por lo que su mensaje sí puede influir en personas que compartan esta creencia. El lenguaje empleado trata de ser neutro, hasta que utiliza la expresión "que no te engañen". El medio utilizado no permite una respuesta inmediata de la audiencia. El autobús no busca una confrontación directa con el colectivo trans, sino que se asuma que la reivindicación de sus derechos no tiene sentido. Se trata de emitir un mensaje que vaya calando poco a poco en la sociedad. Si bien, en los lugares donde se difundió el mensaje pudo haberse mezclado con acciones de violencia, intimidación, hostilidad o discriminación.

\footnotetext{
${ }^{99}$ Memorándum Explicativo de la Recomendación de Política General n ${ }^{\circ} 15$ relativa a la lucha contra el discurso de odio elaborado por la Comisión Europea contra el Racismo y la Intolerancia, la denominada ECRI, de 8 de diciembre de 2015. Explicación de la Recomendación nº 10, párrafo 173.

100 Memorándum Explicativo de la Recomendación de Política General n 15, párrafo 16.
} 


\section{Polít. Crim. Vol. 16, № 31 (Junio 2021), Art. 11, pp. 284-320 [http://politcrim.com/wp-content/uploads/2021/07/Vol16N31A11.pdf]}

En el caso del twittero, en relación con las tensiones sociales existentes, ocurre lo mismo. Qué duda cabe que la violencia de género es la máxima expresión de la discriminación por razón de género y que se trata de un problema social contra el que se lleva años intentando acabar y que, sin embargo, persiste. A pesar de esto, no existen tensiones sociales al respecto. No hay enfrentamientos sociales cuando se produce un homicidio de una mujer en un contexto de violencia de género. Toda la sociedad rechaza estos actos. ${ }^{101}$

El sujeto que realiza las manifestaciones no es alguien influyente socialmente, pero tampoco en las redes sociales. Cuenta con dos mil seguidores en una red social de 340 millones de usuarios activos. El lenguaje empleado resulta ofensivo, violento, si bien implica más un deseo que una incitación a la violencia. Finalmente, el medio empleado no permite una respuesta inmediata de la audiencia y el lugar de difusión tampoco es adecuado para que el mensaje se mezcle con acciones de violencia, etc.

De este modo, podemos concluir, conforme a los criterios de la ECRI que en el caso del twittero no se cumple ninguno, ${ }^{102}$ mientras que en el autobús de Hazte Oír, sí. Sin embargo, como ya hemos adelantado, este último se archivó, mientras que el del twittero llegó al Tribunal Supremo quien consideró en Sentencia 72/2018 que se colmaba el tipo del artículo 510.1 del Código Penal porque "Se trata de un tipo penal estructurado bajo la forma de delito de peligro, bastando para su realización, la generación de un peligro que se concreta en el mensaje con un contenido propio del "discurso de odio"”.

Confiamos en no ser sospechosos de compartir las manifestaciones vertidas por el twittero. Sin embargo, no podemos admitir su calificación como acto delictivo. Entendemos que con la redacción anterior no habría habido dudas ya que no se crea ni siquiera una situación de peligro hipotético para el bien jurídico protegido. Con la redacción actual, queda al arbitrio del juzgador y parece que el Tribunal Supremo aboga por una interpretación ilimitada de "fomentar, promover o incitar de forma directa o indirecta".

\section{Modalidades agravadas}

Con la reforma de 2015 se incorporaron dos modalidades agravadas en los apartados 3 y 4 del artículo 510. La primera supone la aplicación de la pena en su mitad superior "cuando los hechos se hubieran llevado a cabo a través de un medio de comunicación social, por medio de internet o mediante el uso de tecnologías de la información, de modo que, aquel se hiciera accesible a un elevado número de personas."; la segunda prevé la imposición de la pena en su mitad superior, pudiendo elevarse hasta la superior en grado, "cuando los hechos, a la vista de sus circunstancias, resulten idóneos para alterar la paz pública o crear un grave sentimiento de inseguridad o temor entre los integrantes del grupo".

Tal y como avanzamos, se ha criticado que se convierta en modalidad agravada el uso de redes sociales o de internet para la difusión del discurso de odio, cuando en la actualidad es la vía ordinaria de ejecución. La Circular 7/2019 de la Fiscalía General del Estado entiende

101 Con independencia de que, en los últimos tiempos, se haya reabierto un debate que parecía superado, relacionado con el tratamiento de la violencia de género de manera diferencial a otras violencias.

102 GÓMEZ (2018), pp. 447-448 llega a la misma conclusión aplicando el Test de Rabat. 


\section{TAPIA, Patricia: "El discurso de odio del art. 510.1.a) del Código Penal español: la ideología como un Caballo de Troya entre las circunstancias sospechosas de discriminación".}

que "el fin último de la agravación es el aumento de la potencialidad del perjuicio causado" a la víctima o a las víctimas, "mediante la utilización de un medio de comunicación masivo" (p. 63). En este contexto, la misma Circular establece que no es necesario demostrar "que un número de personas haya leído efectivamente el mensaje, pero sí que un número indeterminado de personas haya tenido la posibilidad real de haber accedido al mensaje difundido masivamente". Aquí, nosotros nos preguntamos qué ocurre si alguien, con menos de cincuenta seguidores en Twitter, escribe un twit incitando a la discriminación de un colectivo y uno de sus seguidores, con una repercusión importante dentro de la red social, retwittea su mensaje.

Al margen de esto, se plantean dudas en torno a si las manifestaciones vertidas en un grupo de Facebook cerrado al público o en un grupo de WhatsApp, puede considerarse que se realizan con publicidad y, de ser así, si satisfacen el desvalor de la modalidad agravada. Parece que, en el caso de los grupos de Facebook no cabe duda de que las manifestaciones vertidas se realizan con publicidad. Si bien, cuando se trata de grupos restringidos no se contemplaría la modalidad agravada. Se entiende que realizar manifestaciones en estos grupos se asemeja a realizarlas en la calle, ante una multitud. ${ }^{103}$ La potencialidad de que el mensaje sea accesible a un elevado número de personas, no es la misma que si se tratase de una publicación de Facebook abierta. En el caso de los grupos de WhatsApp, no hemos encontrado una pauta jurisprudencial. No obstante, entendemos que debe distinguirse entre los grupos en los que el número de integrantes es limitado, por lo que se pueden calificar de espacios privados, siendo similar a realizar un comentario en la barra de un bar; frente a aquellos grupos en los que el número de participantes es muy amplio y sigue teniendo nuevas incorporaciones. Estos grupos masivos, entendemos que deberían considerarse igual que los grupos de Facebook, por lo que se consideraría que el mensaje se realiza con publicidad, aunque no se valoraría el medio empleado de manera autónoma.

La segunda de las modalidades agravadas rompe con la interpretación constitucional y del Tribunal Europeo de Derechos Humanos por la que se admite la punibilidad del denominado discurso de odio. Si la idoneidad de los hechos para alterar la paz pública o crear un grave sentimiento de inseguridad o temor entre los integrantes del grupo es una modalidad agravada, entonces, ¿Cuándo estamos ante el tipo básico? ¿Únicamente ante manifestaciones ofensivas cuya declaración no altere la paz pública ni suponga la creación de un sentimiento de inseguridad o temor? Esto no es admisible. ${ }^{104}$

No obstante, en una apuesta por ofrecer una interpretación lege lata, Landa propone que se realice una interpretación "restrictiva férrea" de la modalidad, de modo que comprenda únicamente situaciones "de tal gravedad que el colectivo, sus miembros, puedan "razonablemente" dar por perdida de forma radical la confianza en que las instituciones democráticas les pueden brindar el mínimo de seguridad para poder ejercer sus derechos

\footnotetext{
${ }^{103}$ Por ejemplo, Audiencia Provincial de Barcelona (Sección 10a) Sentencia núm. 299/2019 de 21 mayo. "ha de considerarse que el [mensaje] pudo trascender a un grupo considerable de personas, más elevado que el que podría haber sido testigo del mismo de producirse en plena vía pública".

${ }^{104}$ En este sentido, entre otros, GORJÓN (2019), pp. 218-219.
} 


\section{Polít. Crim. Vol. 16, № 31 (Junio 2021), Art. 11, pp. 284-320 [http://politcrim.com/wp-content/uploads/2021/07/Vol16N31A11.pdf]}

fundamentales. Es una situación por tanto próxima a la explosión o enfrentamiento colectivo: enfrentamiento real, material, no puramente ideal o potencial". ${ }^{105}$

\section{Penalidad}

Finalmente, en relación con la penalidad, en el anterior artículo 510 se preveía la misma sanción para todos los tipos penales que en él se comprendían: prisión de uno a tres años y multa de seis a doce meses. Esta era valorada por la generalidad de la doctrina como desproporcionada debido a que no dejaba de ser una acción incitadora, "provocadora" de otra y, aun así, por ejemplo, resultaba más elevada que la del delito de discriminación en la prestación de servicios públicos, prevista en el precepto siguiente, la cual sí lesionaba el bien jurídico protegido.

Con la reforma de marzo de 2015 se ha modificado la pena, previéndose "una pena de prisión de uno a cuatro años y multa de seis a doce a meses" para los supuestos previstos en el apartado 1 del artículo 510. De este modo, se ignora totalmente la crítica doctrinal ya que se mantiene el límite mínimo y se agrava el máximo. Dicho límite máximo, como se acaba de señalar, podrá llegar a alcanzar los 6 años, si se aplican las modalidades agravadas de los apartados 3 y 4 del precepto.

Y a esto, se debe añadir la posibilidad de imponer una pena de inhabilitación especial para profesión u oficio educativos, en el ámbito docente, deportivo y de tiempo libre, por un tiempo superior al de la duración de la pena de privación de libertad impuesta en su caso a la sentencia, entre tres y diez años (apartado 5). Se trata de una pena muy criticada por la doctrina $^{106}$.

\section{Reflexión final}

Si realizamos una búsqueda en internet de la expresión "delitos de odio" nos aparecen aproximadamente 460 mil resultados en el apartado de noticias, en 0.18 segundos. Las tres primeras páginas pertenecen al mes de abril de 2020, momento en el que escribimos estas palabras.

Esto es solo una muestra de la magnitud actual del uso (bajo nuestro punto de vista, abuso) de esta categoría delictiva por parte de los medios de comunicación y de los operadores jurídicos. En esta tendencia expansiva ha contribuido, indubitadamente, la modificación del artículo 510 del año 2015. Como se ha pretendido poner de manifiesto en las páginas anteriores, la actual previsión del apartado 1.a) del citado artículo resulta tan imprecisa que cabe prácticamente todo. En este contexto, lo que más nos alarma, es su aplicación por parte de los operadores jurídicos, ya que permite crear noticias que, por un lado, corroboran el imaginario social de lo que son los delitos de odio (delito vinculado al sentimiento de odio), y por otro, alimentan la sensación de desamparo cuando en el proceso jurisdiccional se determina que tal conducta no constituye un delito.

\footnotetext{
${ }^{105}$ LANDA (2018), p. 87.

${ }^{106}$ La doctrina critica esta sanción por ir en contra de la libertad de cátedra. Véase, LANDA (2018), p. 88; o PORTILLA (2017), p. 103, entre otros.
} 


\section{TAPIA, Patricia: "El discurso de odio del art. 510.1.a) del Código Penal español: la ideología como un Caballo de Troya entre las circunstancias sospechosas de discriminación".}

Bajo nuestro punto de vista, la pérdida de legitimidad de estos delitos se inició en el momento en el que se adoptó de manera generalizada una terminología confusa y, por lo tanto, inadecuada. Somos conscientes de que la discusión doctrinal sobre la denominación hate crime hate speech, o delito de odio, discurso de odio, está superada. ${ }^{107}$ La generalidad de la doctrina ha arrojado (o hemos arrojado) la toalla frente a un debate baladí: es la terminología utilizada en el ámbito anglosajón, en instancias internacionales, en la Unión Europea y, lo que supone un punto de no retorno, en la sociedad. Pero esto no obsta para poner de manifiesto los efectos perniciosos que ha tenido su asunción.

Con anterioridad al uso "delito de odio" o "delito de discurso de odio", se reservaba la ideología, como causa sospechosa de discriminación, a supuestos en los que intervenían grupos ideológicamente extremos y radicalizados. Al respecto ya nos referimos al célebre caso de Carlos Palomino. Sin embargo, en la actualidad, la vinculación del delito con el término "odio" provoca que se quiera reconocer un mayor injusto en toda conducta delictiva realizada con un sentimiento negativo (odio, ira, rabia, etc.) o, lo que es peor, que cualquier conducta o manifestación revestidas de dicho sentimiento, se califiquen de delictivas. De este modo, se convierte a la ideología en un auténtico caballo de Troya.

Obviamente, toda manifestación que se realiza verbalmente es fruto de la ideología personal: insultos racistas, prejuicios LGTB-fóbicos, expresiones machistas, valoraciones negativas sobre el adversario político, manifestaciones de rechazo hacia quien puede verse expuesto a una enfermedad contagiosa, o hacia alguna profesión en la que se utilicen y/o maltraten animales... todo ello, de un modo u otro, se puede reconducir a la ideología de quien se expresa así. Y, en todos estos casos, este pensar, esta ideología, podría reconducirse a algún sentimiento negativo cercano al odio respecto de quien es objeto del mensaje (o víctima de una agresión). Pero esto no significa que la ira, el odio o la rabia deban precisar de una valoración jurídica, tal y como se ha visto obligado a recordar el Tribunal Supremo, en Sentencia 3124/2019, de 9 de octubre. Asimismo, en la misma resolución, el Alto Tribunal también ha advertido que la aplicación de la circunstancia agravante genérica antidiscriminatoria se refiere a la víctima y debe considerarse solo en situaciones necesitadas de especial protección. Sin embargo, no podemos ignorar que esta resolución cuenta con un voto particular que discrepa con esta interpretación y, además, tampoco es la línea defendida por la Fiscalía General del Estado. En concreto, ya indicamos que en la Circular 7/2019 se defendía una interpretación tan amplia que resulta imposible no tutelar a través del delito de discurso de odio (o delito de odio) la ideología neonazi. Y esto, reiteramos, nos parece un absoluto despropósito.

Entendemos que la adopción de la nueva terminología no puede, ni debe, desvincularse de la categoría delictiva con la que se identifica necesariamente, esta es, los delitos antidiscriminatorios. ${ }^{108}$ Por lo tanto, los delitos de discurso de odio deberán ser delitos de

\footnotetext{
107 Sobre ello, TAPIA (2017), pp. 356-363.

${ }^{108}$ En este sentido se manifiesta claramente LAURENZO (2019), p. 462; de modo similar LASCURAÍN (2012), p. 104; o IBARRA (2012), p. 19, entre otros.
} 


\section{Polít. Crim. Vol. 16, № 31 (Junio 2021), Art. 11, pp. 284-320 [http://politcrim.com/wp-content/uploads/2021/07/Vol16N31A11.pdf]}

discurso discriminatorio. ${ }^{109}$ Esto delimita el bien jurídico (deberá ser el valor no ser discriminado) y el sujeto pasivo (vinculado a un colectivo que se encuentra en una posición de inferioridad o incluso marginación dentro de la sociedad), legitimando, así, la intervención del ius puniendi.

Compartimos estas bases con el Grupo de Estudios de Política Criminal, que ha propuesto una reforma del artículo 510.1.a), de manera que quede redactado de la siguiente manera: "La incitación pública y directa por motivos discriminatorios a la comisión de delitos contra la vida, la integridad física y psíquica, la integridad moral, la igualdad, la libertad, la libertad sexual, de daños, de genocidio y de lesa humanidad, contra grupos vulnerables o sus miembros que genere riesgo inminente de que se puedan cometer uno o varios de dichos delitos, será castigada con una pena de prisión de uno a tres años. En el caso de que el delito a cuya comisión se incite tuviera prevista una pena de igual o inferior gravedad, se impondría esta rebajada en un grado".

Nos parece acertada esta propuesta en la medida en que se vincula la incitación a una conducta delictiva y no a un mero sentimiento o a un actuar que, de materializarse, no tiene por qué ser punible, como ocurre en la actualidad. Además, se limita también el adelantamiento de las barreras de protección al establecer que la incitación debe implicar un riesgo inminente de que se cometan uno o varios delitos. Asimismo, se limita el sujeto pasivo y se tiene en cuenta el principio de proporcionalidad en la determinación de la pena.

No obstante, no podemos suscribir la propuesta de manera absoluta. Entendemos que no resulta adecuada la enumeración de un numerus clausus de conductas delictivas. Por otro lado, aunque estamos de acuerdo en delimitar claramente el sujeto pasivo, consideramos que sería más adecuado aludir a grupos o colectivos susceptibles de ser discriminados, en vez de utilizar el término vulnerable ${ }^{110}$. Finalmente, en lo que a la pena se refiere, consideramos que debería preverse, de manera alternativa, la previsión de una pena de multa. Es cierto que, con lo previsto en la propuesta del Grupo de Estudios de Política Criminal, en el supuesto de los delitos menos graves se impondrá la pena inferior en un grado a la prevista en el delito al que se incita. Pero, entendemos que sería conveniente dar ese margen de arbitrio al juzgador, en atención a la gravedad de los hechos.

Por su parte, DÍAZ (2013), p. 102: "se ha llegado a distinguir conceptualmente en nuestro ordenamiento entre delitos de odio (cometidos por "motivos discriminatorios") y delitos de discriminación, donde la discriminación se encuentra en los efectos del delito para el sujeto discriminado, no en las motivaciones del autor.". pp. 143 y ss. entendemos que, para el autor, los delitos de discriminación son una categoría dentro de los delitos de odio. ${ }^{109}$ Si bien, tal y como recuerda GORJÓN (2019), p. 221 "El Derecho penal cuenta con otros preceptos que tienen como finalidad proteger a determinados colectivos minoritarios, que no son tradicionalmente discriminados en nuestro país, como la Monarquía, a través de las injurias a la Corona de los artículos. 490.3 y art. $491 \mathrm{CP}$ por ejemplo. Por tanto, no todo discurso de odio político pertenece a la categoría del derecho penal antidiscriminatorio." No obstante, nos cuestionamos si, siendo esto así, es adecuado considerar tales delitos como delitos de discurso de odio.

${ }^{110}$ En la línea defendida por LAURENZO (2013), pp. 77 y ss., donde distingue entre víctimas vulnerables, cuyas características intrínsecas les sitúan en esa posición de debilidad o dependencia, como ocurriría con los menores o personas de avanzada edad, frente a las víctimas vulneradas. 
TAPIA, Patricia: "El discurso de odio del art. 510.1.a) del Código Penal español: la ideología como un Caballo de Troya entre las circunstancias sospechosas de discriminación".

En cualquier caso, no deja de ser relevante el esfuerzo realizado por este grupo, y por otros autores y autoras, cinco años después de la reforma para mantener vivo el debate en torno a la necesidad de otorgar seguridad jurídica en el ámbito de los mal denominados delitos de odio (delitos de discurso de odio). 


\section{Referencias bibliográficas}

ALONSO ÁLAMO, Mercedes (2014): Bien jurídico penal y Derecho penal mínimo de los Derechos Humanos (Valladolid, Universidad de Valladolid).

AGUILAR GARCÍA, Miguel Ángel et al (2015): Manual práctico para la investigación y enjuiciamiento de delitos de odio y discriminación (Barcelona, Centre d'Esudis Jurídics i Formació Especialitzada).

ALASTUEY DOBÓN, M Marmen (2016): "Discurso del odio y negacionismo en la reforma del Código Penal de 2015”, en: Revista Electrónica de Ciencia Penal y Criminología (no 18-14), pp. 1-38.

ALCÁCER GUIRAO, Rafael (2019): "Símbolos y ofensas. Crítica a la protección penal de los sentimientos religiosos", en: Revista Electrónica de Ciencia Penal y Criminología (21-15), pp. 1-38.

ANDEREZ BELATEGI, Mikel (2019): "La protección institucional a través del discurso de odio: problemática general con especial referencia al caso "Sacca Terentyev c. Rusia”", en: ALONSO RIMO, Alberto (dir.), COLOMER BEA, David (coord.), Derecho penal preventivo, orden público y seguridad ciudadana (Navarra, Aranzadi), pp. 511-538.

BAGES SANTACANA, Joaquín (2019): La protección penal de los sentimientos religiosos. Especial referencia a la ponderación de bienes jurídico-penales (Valencia, Tirant lo Blanch).

BERNAL DEL CASTILLO, Jesús (1998): La discriminación en el Derecho Penal,(Granada, Comares).

BILBAO UBILLOS, Juan $M^{a}$ (2018): "La STEDH de 13 de marzo de 2018 en el asunto Stern Taulats y Roura Capellera contra España: la crónica de una condena anunciada", en: Revista General de Derecho Constitucional (n $\left.{ }^{\circ} 28\right)$, pp. 1-29.

BORJA JIMÉNEZ, Emiliano (1999): Violencia y criminalidad racista en Europa Occidental: la respuesta del Derecho penal (Granada, Comares).

BRANDARIZ GARCÍA, José Ángel (2010): "Victimización de migrantes", en: TAMARIT SUMALLA, Josep (coord.), Víctimas olvidadas (Valencia,Tirant lo Blanch), pp. 4569.

CACHÓN RODRÍGUEZ, Lorenzo (2009): "La discriminación y las políticas antidiscriminación vistas desde el mundo de la inmigración", en: ZUFIAUR

NARVAIZA, José $\mathrm{M}^{\mathrm{a}}$, (coordinador), Los retos de la igualdad en el trabajo (Madrid, Fundación Francisco Largo Caballero), pp. 225-252.

CÁMARA ARROYO, Sergio (2017): "El concepto de delitos de odio y su comisión a través del discurso. Especial referencia al conflicto con la libertad de expresión", en: Anuario de Derecho Penal y Ciencias Penales (vol. LXX), pp. 139-225.

CÁMARA ARROYO, Sergio (2016): "Consideraciones críticas sobre la tutela penal de la libertad religiosa y los delitos contra la libertad de conciencia, los sentimientos religiosos y el respeto a los difuntos", en: Anuario de Derecho Penal y Ciencias Penales (vol. LXIX), pp. 123-210.

CISNEROS ÁVILA, Fátima (2018): Derecho Penal y diversidad cultural. Bases para un diálogo intercultural (Valencia, Tirant lo Blanch), pp. 306

CONDE-PUMPIDO TOURON, Cándido (1996): "La sanción penal de la discriminación; especial referencia a la discriminación por razón de enfermedad y al nuevo delito 
TAPIA, Patricia: "El discurso de odio del art. 510.1.a) del Código Penal español: la ideología como un Caballo de Troya entre las circunstancias sospechosas de discriminación".

de discriminación en el trabajo", en: Cuadernos de Derecho Judicial (nº 1$)$, pp. 283-319.

CÓRDOBA RODA, Juan; GARCÍA ARÁN, Mercedes (dir.) (2004): Comentarios al Código Penal (Madrid, Marcial Pons).

CUERDA ARNAU, Ma Luisa (2019): “Delitos contra la Constitución”, en: GONZÁLEZ CUSSAC, José Luis (coord.), Derecho Penal Parte Especial, 6 ${ }^{\mathrm{a}}$ ed. (Valencia, Tirant lo Blanch), pp. 739-773.

DAUNIS RODRÍGUEZ, Alberto (2020): “El modelo español de protección penal frente a comportamientos de odio", en: GORJÓN BARRANCO, María Concepción, (dir.), GUZMÁN ORDAZ, Raquel; NIETO LIBRERO, Ana Belén, (coord.), Políticas públicas en defensa de la inclusión, la diversidad y el género, (Salamanca, Aquilafuente, Universidad de Salamanca), pp. 1049-1059.

DE PABLO SERRANO, Alejandro Luis (2018): Honor, injurias y calumnias. Los delitos contra el honor en el Derecho histórico español y en el derecho vigente (Valencia, Tirant lo Blanch y Ediciones de la Universidad de Valladolid).

DE PABLO SERRANO, Alejandro L.; TAPIA BALLESTEROS, Patricia (2017): "Discurso de odio: problemas en la delimitación del bien jurídico y en la nueva configuración del tipo penal”, en: Diario La Ley (nº 8911, 30 de enero), pp. 1-8.

DE VICENTE MARTÍNEZ, Rosario (2018): El discurso del odio. Análisis del artículo 510 del Código Penal (Valencia, Tirant lo Blanch).

DEL ROSAL BLASCO, Bernardo (2004): "Delitos contra la Constitución (V). Delitos relativos al ejercicio de los derechos fundamentales y libertades públicas, y al deber de cumplimiento de la prestación social sustitutoria", en COBO DEL ROSAL, Manuel (coord.) Derecho Penal Español. Parte Especial (Madrid, Dykinson, S.L.), pp. 1035-1050.

DÍAZ LÓPEZ, Juan Alberto (2018): Informe de delimitación conceptual en materia de delitos de odio (Madrid, Estudio encargado por la Comisión de Seguimiento del Convenio de colaboración y cooperación Interinstitucional contra el racismo, la xenofobia y otras formas de intolerancia y financiado por la Secretaría General de Inmigración y Emigración del Ministerio de Empleo y Seguridad Social).

FERNÁNDEZ LÓPEZ, Ma Fernanda (2009): "Las causas de discriminación o la movidad de un concepto", en: Temas laborales: Revista andaluza de trabajo y bienestar social (n' 98$)$, pp. 11-57.

GARCÍA ÁLVAREZ, Pastora (2004): El Derecho Penal y la Discriminación. Especial referencia al extranjero como víctima de discriminación penalmente relevante (Valencia, Tirant lo Blanch).

GÓMEZ MARTÍN, Víctor (2018): “Odio en la red. Una revisión crítica de la reciente jurisprudencia sobre Ciberterrorismo y Ciberodio”, en: Revista de Derecho Penal y Criminología ( $3^{\mathrm{a}}$ época, $\left.\mathrm{n}^{\circ} 20\right)$, pp. 411-449

GÓMEZ MARTÍN, Víctor (2016): “Incitación al odio y género. Algunas reflexiones sobre el nuevo art. $510 \mathrm{CP}$ y su aplicabilidad al discurso sexista”, en: Revista Electrónica de Ciencia Penal y Criminología (nº 18-20), pp. 1-25.

GORJÓN BARRANCO, María Concepción (2019): Ciberterrorismo y delito de odio motivado por la ideología (Valencia, Ediciones Universidad de Salamanca, Tirant lo Blanch). 
GORJÓN BARRANCO, María Concepción (2018): "La inflación penal del discurso discrepante: un análisis a través de la jurisprudencia más reciente", en: Revista Brasileira de Ciências Criminais (vol. 147), pp. 615-642.

GOYENA HUERTA, Jaime (2018): "Algunas cuestiones penales sobre el discurso del odio", en: Revista Aranzadi de Derecho y Proceso Penal ( ${ }^{\circ}$ 49), s/p.

GUTIÉRREZ MAYO, Escarlata (2020): “Agravante de género, de sexo y de parentesco, aplicación práctica y compatibilidad", en: ORTEGA BURGOS, Enrique (dir.), Derecho Penal 2020 (Valencia, Tirant lo Blanch), pp. 305-323.

IBARRA BLANCO, Esteban (2012): "Racismo, víctimas y delitos de odio", en: GARCÍA GARCÍA, Ricardo y DOCAL GIL, David, (dir.), Grupos de odio y violencias sociales (Madrid, Rasche), pp. 13-22.

LANDA GOROTIZA, Jon Mirena (2000): La intervención penal frente a la xenofobia. Problemática general con especial referencia al «delito de provocación» del artículo 510 del Código Penal (Bilbao, Universidad del País Vasco).

LANDA GOROSTIZA, Jon Mirena (2001): La política criminal contra la xenofobia y las tendencias expansionistas del derecho penal, (Granada, Comares).

LANDA GOROSTIZA, Jon Mirena (2018): Los delitos de odio. Artículos 510 y $22.4^{\circ} \mathrm{CP}$ 1995 (Valencia, Tirant lo Blanch).

LASCURAÍN SÁNCHEZ, Juan Antonio (2012): “Cómo prevenimos los delitos de discriminación?”, en: GARCÍA GARCÍA, Ricardo (dir.) Grupos de odio y violencias sociales (Madrid, Rasche), pp. 23-38.

LAURENZO COPELLO, Patricia (2019): "La manipulación de los delitos de odio", en: POMARES CINTAS, Esther; FUENTES OSORIO, Juan Luis. (coord.), VELÁSQUEZ VELÁZQUEZ, Fernando; PORTILLA CONTRERAS, Guillermo (directores), Un juez para la democracia: libro homenaje a Perfecto Andrés Ibáñez (Madrid, Dykinson), pp. 453-468

LAURENZO COPELLO, Patricia (2018): "Sentimientos religiosos y delitos de odio: un nuevo escenario para unos delitos olvidados", en: VV.AA., Liber Amicorum. Estudios Jurídicos en Homenaje al Prof. Dr. Dr. H.c. Juan $\mathrm{M}^{\mathrm{a}}$. Terradillos Basoco (Valencia, Tirant lo Blanch), pp. 1287-1300.

LAURENZO COPELLO, Patricia (2013): “ ¿Vulnerables o vulnerados? Las paradojas de la tutela penal de los inmigrantes", en: DE HOYOS SANCHO, Montserrat (dir.), Garantías y derechos de las víctimas especialmente vulnerables en el marco jurídico de la Unión Europea (Valencia, Tirant lo Blanch), pp. 75-88.

LAURENZO COPELLO, Patricia (2009): "El modelo de protección penal de los inmigrantes: de víctimas a excluidos", en: CARBONELL MATEU, Juan Carlos; GONZÁLEZ CUSSAC, José Luis; ORTS BERENGUER, Enrique; MAQUEDA ABREU, $M^{a}$ Luisa (coord.), Constitución, derechos fundamentales y sistema penal (semblanzas y estudios con motivo del setenta aniversario del profesor Tomás Salvador Vives Antón (Valencia, Tirant lo Blanch), pp. 1149-1172.

LAURENZO COPELLO, Patricia (1996a): "Los preceptos relativos a la discriminación en el Código Penal de 1995. Origen y enumeración”, en: Discriminación en el Código Penal de 1995 (Estudios Penales Criminológicos XIX), pp. 219-288.

LAURENZO COPELLO, Patricia (1996b): "La discriminación en el Código Penal", en: Estudios Penales y Criminológicos (nº 19), pp. 219-288. 
TAPIA, Patricia: "El discurso de odio del art. 510.1.a) del Código Penal español: la ideología como un Caballo de Troya entre las circunstancias sospechosas de discriminación".

MACHADO RUIZ, Dolores (2002): La discriminación en el ámbito de los servicios públicos: análisis del art. $511 \mathrm{CP}$ (Valencia, Tirant lo Blanch).

MARKEFKA, Manfred (1990): Vorurteile, Minderheiten, Diskriminierung (Luchterhand, Neuwied).

MARTÍN ARAGÓN, Ma Mar (2019): “Incidentes LGTBIQ-Fóbicos en España: más allá de los delitos de odio", en: Revista Electrónica de Estudios Penales y de la Seguridad ( ${ }^{\circ} 5$ especial), pp. 1-17.

MIRÓ LLINARES, Fernando (2017): "Derecho Penal y 140 caracteres. Hacia una exégesis restrictiva de los delitos de expresión”, en: MIRÓ LLINARES, Fernando (dir) Cometer delitos en 140 caracteres. El Derecho penal ante el odio y la radicalización en Internet (Madrid, Marcial Pons), pp. 21-66.

MORETÓN TOQUERO, M M Aranzazu (2012): "El "ciberodio", la nueva cara del mensaje de odio: entre la cibercriminalidad y la libertad de expresión”, en: Revista Jurídica de Castilla y León (n 27, mayo), pp. 1-18.

MUÑOZ CONDE, Francisco (2009): Derecho Penal. Parte Especial, 17 a ed. (Valencia, Tirant lo Blanch).

PÉREZ DEL RÍO, Teresa; DEL REY GUANTER, Salvador; FERNÁNDEZ LÓPEZ, M ${ }^{a}$ Fernanda (1993): Discriminación e igualdad en la negociación colectiva (Madrid, Instituto de la Mujer).

PORTILLA CONTRERAS, Guillermo (2015): "La represión penal del "discurso del odio"”, en: QUINTERO OLIVARES, Gonzalez (dir.), Comentario a la reforma penal de 2015 (Navarra, Thomson Reuters Aranzadi), pp. 717-753.

PORTILLA CONTRERAS, Guillermo (2017): "El retorno de la censura y la caza de brujas anarquistas", en: Miró Llinares, Fernando (dir.), Cometer delitos en 140 caracteres. El Derecho penal ante el odio y la radicalización en Internet (Madrid, Marcial Pons), pp. 87-105.

RAMOS VÁZQUEZ, José Antonio (2019): "Muerte y resurrección del delito de escarnio en la jurisprudencia española", en: Revista Electrónica de Ciencia Penal y Criminología (n²1-17), pp. 1-49.

REY MARTÍNEZ, Fernando (2010): "Igualdad entre mujeres y hombres en la jurisprudencia del Tribunal Constitucional español” en MORA RUIZ, Manuela (dir.), Formación y objeto del Derecho antidiscriminatorio de género: Perspectiva sistemática de la igualdad desde el Derecho público (Reus, Atelier, Reus), pp. 77-110.

ROCA DE AGAPITO, Luis (2017): "El delito de escarnio de los sentimientos religiosos", en: Anuario de Derecho Eclesiástico del Estado (vol. XXXIII), pp. 557-597.

RODRÍGUEZ YAGÜE, Cristina (2007): La tutela penal del derecho a no ser discriminado (Análisis de los artículos 511 y 12 del Código Penal) (Albacete, Bomarzo).

ROTTLEUTHNER, Hubert y MAHLMANN, Matthias (2011): Diskriminierung in= Deutschland (Baden-Baden, Vermutungen und Fakten, Nomos).

SANZ MULAS, Nieves (2017): Delitos culturalmente motivados (Valencia, Tirant lo Blanch)

SERRANO GÓMEZ, Alfonso; SERRANO MAILLO, Alfonso (2007): Derecho Penal: Parte especial, $12^{\mathrm{a}}$ ed. (Madrid, Dykinson). 
TAPIA BALLESTEROS, Patricia (2017): "Identificación de las víctimas de los delitos de odio: Aproximación a algunos de los problemas que plantea esta categoría delictiva", en: DE HOYOS SANCHO, Montserrat, (directora) La víctima del delito y las últimas reformas procesales penales, (Navarra, Thomson Reuters, Aranzadi), pp. 355-371.

TAPIA BALLESTEROS, Patricia (2014): La discriminación laboral. Análisis del artículo 314 del Código Penal (Valencia, Tirant lo Blanch).

TAPIA BALLESTEROS, Patricia (2015): "La tutela penal de las personas transexuales (en relación con la Sentencia 111/2014, de 13 de marzo de 2014, Juzgado de lo Penal no seis de Barcelona. Procedimiento Abreviado 518/2013)" en: Revista de Derecho y Proceso Penal (n 36), pp. 183-194.

TAPIA BALLESTEROS, Patricia (2010): “Comentario al artículo 510”, en: GÓMEZ TOMILLO, Manuel, (dir.), Comentarios al Código Penal, $1^{\mathrm{a}}$ ed. (Valladolid, Lex Nova), pp. 1958-1962. 